\title{
NFAT/Fas signaling mediates the neuronal apoptosis and motor side effects of GSK-3 inhibition in a mouse model of lithium therapy
}

\author{
Raquel Gómez-Sintes and José J. Lucas \\ Centro de Biología Molecular "Severo Ochoa” (CBM“SO”), CSIC/UAM, Madrid, \\ and Centro de Investigación Biomédica en Red sobre Enfermedades Neurodegenerativas (CIBERNED), Instituto de Salud Carlos III, Spain.
}

\begin{abstract}
Use of lithium, the mainstay for treatment of bipolar disorder, is limited by its frequent neurological side effects and its risk for overdose-induced toxicity. Recently, lithium has also been proposed as a treatment for Alzheimer disease and other neurodegenerative conditions, but clinical trials have been hampered by its prominent side effects in the elderly. The mechanisms underlying both the positive and negative effects of lithium are not fully known. Lithium inhibits glycogen synthase kinase-3 (GSK-3) in vivo, and we recently reported neuronal apoptosis and motor deficits in dominant-negative GSK-3-transgenic mice. We hypothesized that therapeutic levels of lithium could also induce neuronal loss through GSK-3 inhibition. Here we report induction of neuronal apoptosis in various brain regions and the presence of motor deficits in mice treated chronically with lithium. We found that GSK-3 inhibition increased translocation of nuclear factor of activated T cells $c 3 / 4$ (NFATc3/4) transcription factors to the nucleus, leading to increased Fas ligand (FasL) levels and Fas activation. Lithium-induced apoptosis and motor deficits were absent when NFAT nuclear translocation was prevented by cyclosporin A administration and in Fas-deficient $l p r$ mice. The results of these studies suggest a mechanism for lithium-induced neuronal and motor toxicity. These findings may enable the development of combined therapies that diminish the toxicities of lithium and possibly other GSK-3 inhibitors and extend their potential to the treatment of Alzheimer disease and other neurodegenerative conditions.
\end{abstract}

\section{Introduction}

Since its introduction into psychiatric pharmacotherapy 60 years ago, lithium remains the most effective agent in the treatment and prophylaxis of major mood disorders, particularly bipolar disorder (BD) (1-4). Despite the obvious advantages of chronic lithium therapy, its clinical use is often curtailed by its narrow therapeutic index and its devastating overdose-induced toxicity (5). Accordingly, patients must be closely monitored not only at the beginning of treatment, but also during treatment maintenance, to keep serum lithium concentrations within a therapeutic window of $0.6-1.4 \mathrm{mM}$. Even within this therapeutic range, mild neurological side effects such as hand tremor are common, and progressive toxicity to marked neurological impairment correlates with increasing serum levels above $1.5 \mathrm{mM}$ (5). The biochemical and cellular basis for lithium's therapeutic efficacy and the precise molecular mechanisms through which it exerts its unwanted neurological side effects remain to be fully elucidated.

One of the molecular targets postulated to mediate lithium's biological effects is glycogen synthase kinase-3 (GSK-3). This is a serine/ threonine kinase that is present in most tissues and that is particularly abundant in the CNS (6). This enzyme has 2 isoforms (GSK-3 $\alpha$ and GSK-3 $\beta$ ) and participates in multiple signaling cascades such as the insulin and Wnt pathways $(6,7)$. GSK-3 has the peculiarity of being active in resting conditions, with activation of the above-mentioned signaling pathways resulting in GSK-3 inhibition by phosphorylation on a serine residue on its $N$ terminus (Ser21 and Ser9 in GSK-3 $\alpha$ and GSK-3 $\beta$, respectively) (8). The many well-characterized phosphorylation substrates of GSK-3 include cytoskeletal pro-

Conflict of interest: The authors have declared that no conflict of interest exists. Citation for this article: J Clin Invest. 2010;120(7):2432-2445. doi:10.1172/JCI37873. teins, transcription factors, and metabolic regulators, highlighting a prominent role for GSK-3 in cellular architecture, gene expression, cell division and fate decision, and apoptosis, among others $(7,8)$. GSK-3 has also been suggested to participate in the pathogenesis of Alzheimer disease $(\mathrm{AD})(9,10)$, as it is the predominant tau kinase in brain $(11,12)$ and an important player in amyloid- $\beta$ production and toxicity $(13,14)$, and mice with increased GSK-3 activity mimic this disease $(15,16)$. Accordingly, GSK-3 inhibitors, including lithium, have been postulated as a potential therapy for AD (17-21). However, clinical trials to assess the efficacy of chronic lithium for $\mathrm{AD}$ are hampered by the above-mentioned toxicity of lithium therapy, particularly in the elderly $(19,22,23)$.

Lithium was found to be an inhibitor of GSK-3 in the last decade $(24,25)$. It directly and reversibly inhibits GSK-3 in vitro, with an $\mathrm{IC}_{50}$ value of approximately $2 \mathrm{mM}(24)$, by acting as a competitive inhibitor of $\mathrm{Mg}^{2+}$ (26). Later, it was found that lithium also inhibits GSK-3 indirectly by promoting inhibitory N-terminal serine phosphorylation in vivo (27-31). This is in part due to a feed-forward process whereby lithium-induced decreases in GSK-3 activity result in inhibition of protein phosphatase-1, which has the ability to remove the inhibitory phosphate in $\operatorname{GSK}-3(29,32,33)$. More recently, lithium has also been found to disrupt the complex formed by $\beta$-arrestin 2 with the phosphatase PP2A and Akt in conjunction with $G$ protein-coupled receptors such as the dopamine D2 receptor (31). This results in increased Akt activity and a subsequent increase in the inhibitory N-terminal phosphorylation of GSK-3 (31).

To explore the neurological consequences of sustained GSK-3 inhibition in vivo, we recently generated transgenic mice that express a dominant-negative form of GSK-3 in forebrain neurons (34). These mice showed increased neuronal apoptosis in the basal ganglia, particularly in the striatum but also in the cortex, and a 
A

Lithium administration paradigm

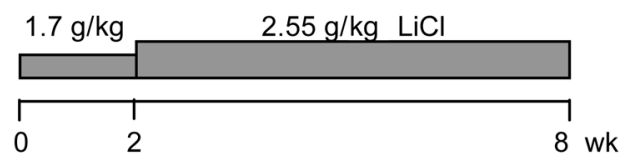

B

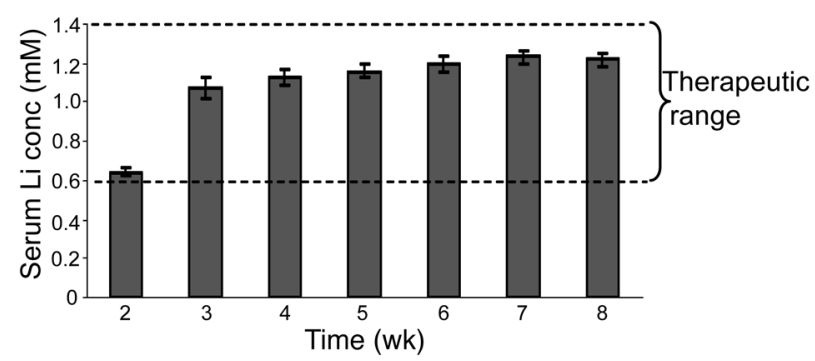

C

GSK-3 activity

Inactive GSK-3 (pSer21/9)
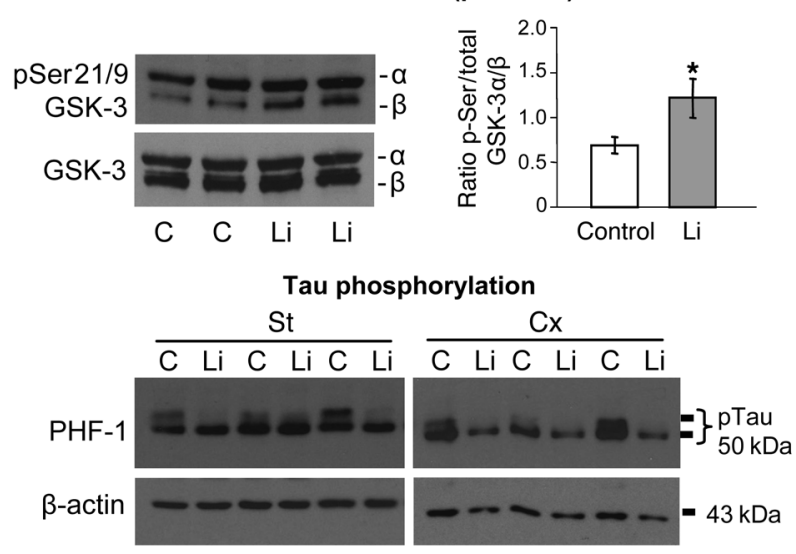

D

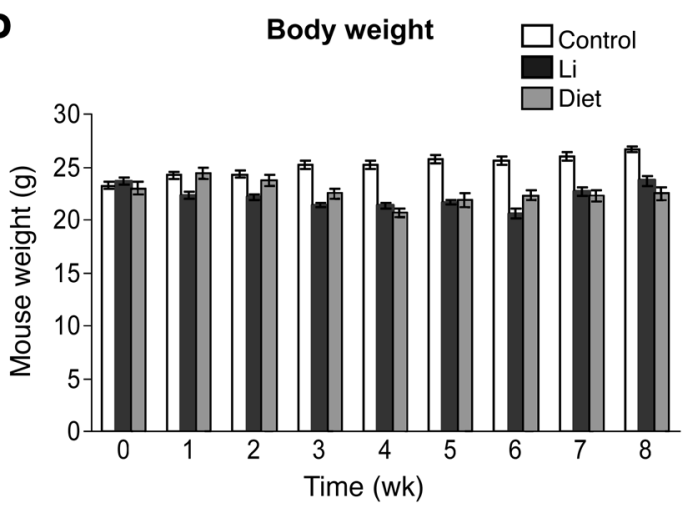

Motor coordination

E

Vertical pole test

F

DigiGait

(stride length variability)
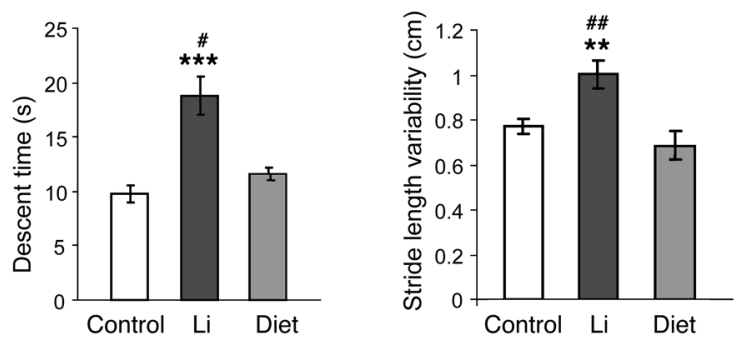

G

DigiGait (step angle variability)

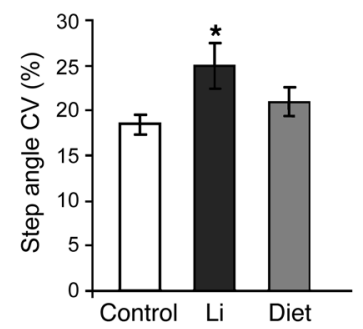

H

DigiGait

(stance asymmetry)

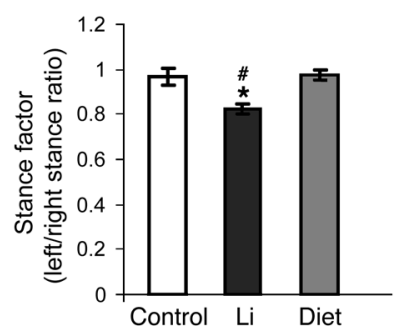

Figure 1

Reduced brain GSK-3 activity and impaired motor coordination induced by chronic lithium administration at therapeutic doses. (A) Diagram showing lithium administration protocol. (B) Lithium plasma levels across the 8 weeks of feeding with lithium-containing chow $(n=38)$. conc, concentration. (C) Upper panels: Western blot detection and quantification of inactive GSK-3 (pSer21/9-GSK-3) in homogenates from striatum of control and lithiumtreated mice (control [C], $n=8$; lithium, $n=8$ ). Lower panels: Western blot detection of phosphorylated tau (PHF-1) in homogenates from striatum (St) and cortex (Cx) of control and lithium-treated mice. (D) Body weight over the course of treatment in control $(n=16)$, lithium-treated ( $n=24)$, and calorie-restricted (diet, $n=8$ ) mice. (E) Descent time in vertical pole test (control, $n=28$; lithium, $n=25$; diet, $n=8$ ). ( $\mathbf{F}-\mathbf{H})$ Analysis of gait parameters in footprint test as measured by DigiGait system (control, $n=23$; lithium, $n=17$; diet, $n=8$ ): stride length variability $(\mathbf{F})$, step angle variability $(\mathbf{G})$, and stance asymmetry $(\mathbf{H}) .{ }^{*} P<0.05,{ }^{* *} P<0.01,{ }^{* \star *} P<0.001$ versus control; ${ }^{\#} P<0.05,{ }^{\# \#} P<0.01$ versus diet.

concomitant deficit in motor coordination tasks (34). In view of the neuronal apoptosis and the neurological phenotype in these mice with decreased GSK-3 activity, we hypothesized that lithium therapy, apart from its well-documented neurological side effects, might also induce neuronal apoptosis. We therefore decided to investigate in wild-type mice whether chronic lithium administration at therapeutic doses, which are known to decrease GSK-3 activity when acutely administered (30), would also result in neuronal apoptosis and motor deficits. Furthermore, we also sought to explore the molecular mechanisms downstream of GSK-3 inhibition by which lithium exerts its neurological toxicity in vivo.

\section{Results}

Chronic lithium administration to mice results in decreased brain GSK-3 activity and impaired motor coordination. In order to explore the potential deleterious consequences of chronic lithium administration to mice, we first established a protocol of $\mathrm{LiCl}$ administration in food pellets resulting in serum lithium concentrations within the upper range of the therapeutic window for treatment and prophylaxis of $\mathrm{BD}$. To achieve this, we gradually increased the dose of lithium over an 8 -week period (Figure 1A). In good agreement with our previous observations (20), feeding mice with a food pellet preparation containing $1.7 \mathrm{~g} \mathrm{LiCl} / \mathrm{Kg}$ for 2 weeks resulted in $0.64 \pm 0.04 \mathrm{mM}$ 

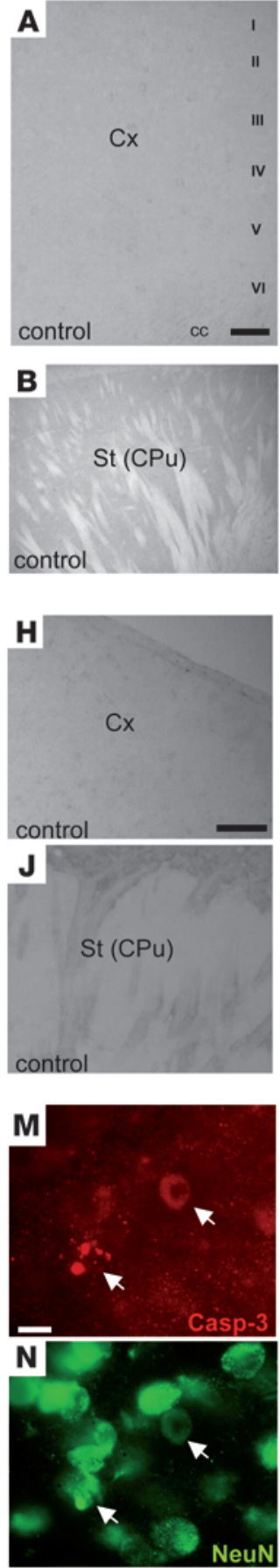
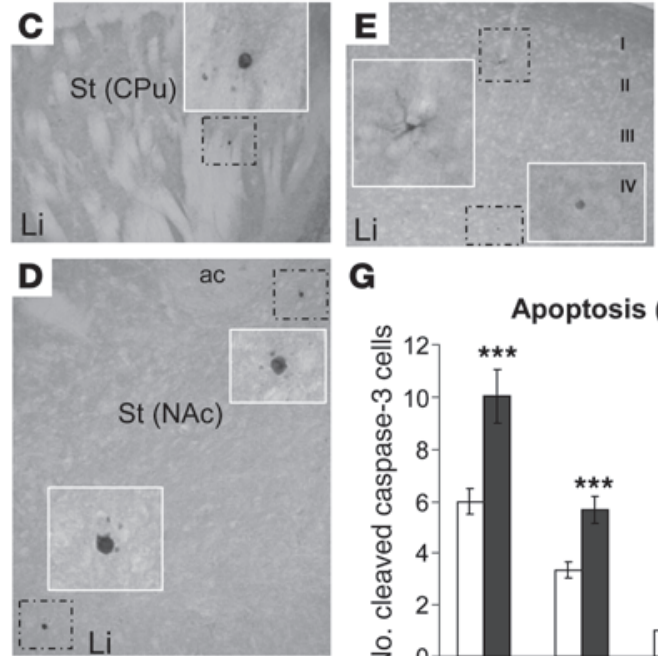

G
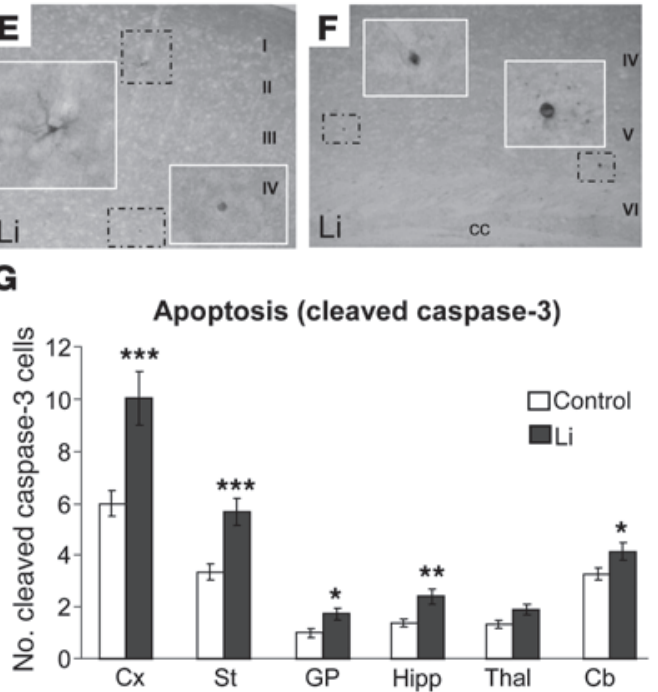

L $\quad$ Apoptosis (TUNEL)
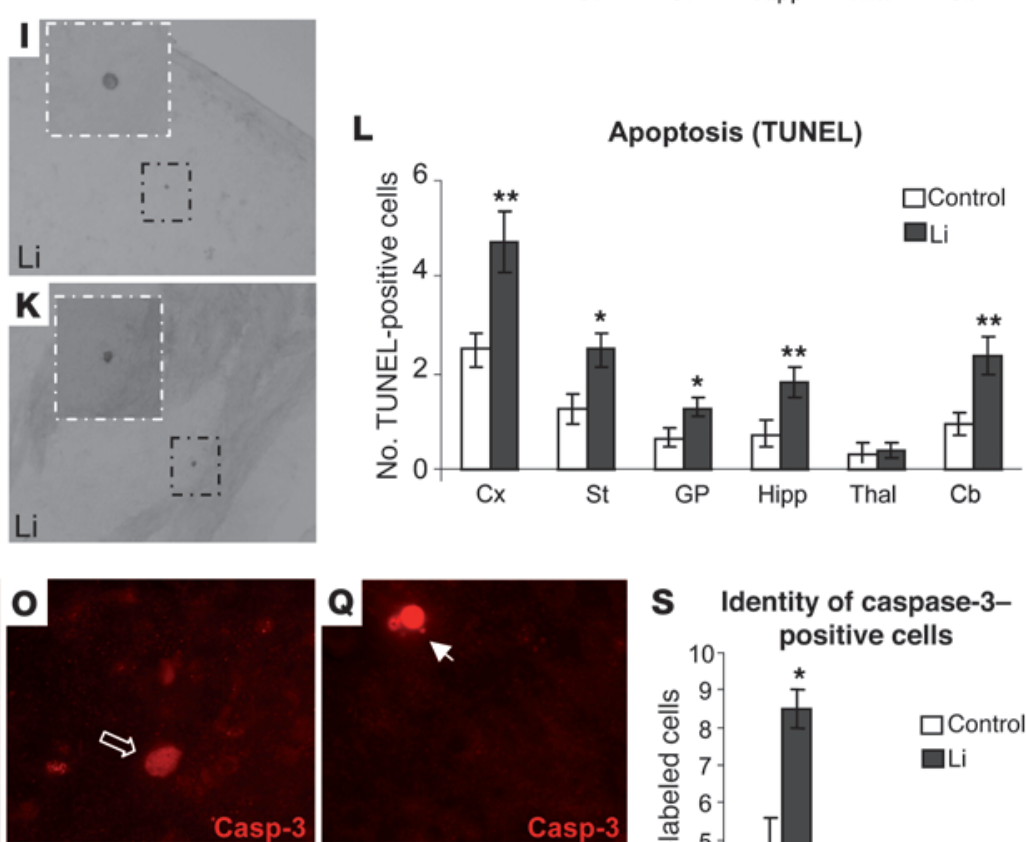

S Identity of caspase-3-

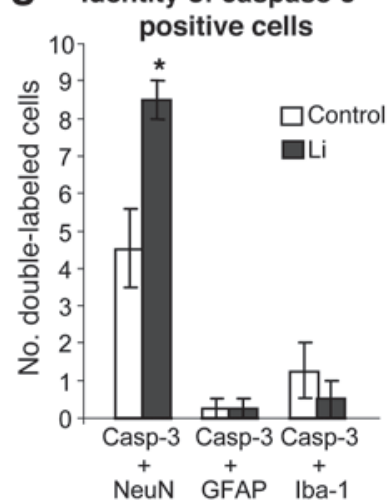

Figure 2

Neuronal apoptosis induced by chronic lithium administration. (A-F) Immunohistochemical detection of cleaved caspase-3-positive cells in cortex $(\mathbf{A}, \mathbf{E}$, and $\mathbf{F})$ and striatum $(\mathbf{B}, \mathbf{C}$, and $\mathbf{D})$ of control $(\mathbf{A}$ and $\mathbf{B})$ and lithium-treated $(\mathbf{C}-\mathbf{F})$ mice. Insets show higher magnifications of the boxed areas. I-VI, layers of the cortex; cc, corpus callosum; CPu, caudate putamen; NAc, nucleus accumbens; ac, anterior commissure. Scale bar in A: $200 \mu \mathrm{m}(\mathbf{A}-\mathbf{F})$. (G) Immunohistochemical quantification of the number of cleaved caspase-3-positive cells per 30-um sagittal section in regions analyzed ( $n=22$ per group, 4 sections per animal). GP, globus pallidus; Hipp, hippocampus; Thal, thalamus; Cb, cerebellum. (H-K) Representative images of TUNEL staining in cortex $(\mathbf{H}-\mathbf{I})$ and striatum $(\mathbf{J}$ and $\mathbf{K})$ of control $(\mathbf{H}$ and $\mathbf{J})$ and lithium-treated $(\mathbf{I}$ and $\mathbf{K})$ mice. Scale bar in H: $200 \mu \mathrm{m}(\mathbf{H}-\mathbf{K})$. (L) Quantification of the number of TUNEL-positive cells per 30- $u \mathrm{~m}$ sagittal section in the different regions analyzed (control, $n=12$; lithium, $n=10)$. (M-R) Representative images of double-labeling immunofluorescence with anti-cleaved caspase-3 and anti-NeuN (M and $\mathbf{N}$ ), GFAP ( $\mathbf{O}$ and $\mathbf{P})$, or Iba-1 $(\mathbf{Q}$ and $\mathbf{R}$ ) antibodies in striatal sections of lithium-treated mice. Scale bar in $\mathbf{M}$ : $10 \mu \mathrm{m}$ ( $\mathbf{M}-\mathbf{R})$. White arrows indicate double-labeled cells; open arrows, caspase-3-positive/GFAP-negative cells. (S) Histogram showing quantification of double staining with caspase-3 antibody (Casp-3) and markers of different cellular types ( $n=8$ per group). ${ }^{*} P<0.05,{ }^{\star \star} P<0.01,{ }^{* \star *} P<0.001$. 
plasma concentration of lithium (Figure 1B). Subsequently, mice were shifted to a food pellet preparation containing $2.5 \mathrm{~g} \mathrm{LiCl} / \mathrm{kg}$ for 6 more weeks, during which serum lithium concentrations were monitored every week. As shown in Figure 1B, plasma levels were above $1.0 \mathrm{mM}$ by week 3 and progressively increased over the following 3 weeks, when they reached a plateau at $1.2 \mathrm{mM}$.

We then verified that this lithium administration paradigm resulted in decreased GSK-3 activity in brain (Figure 1C). Western blot analysis of brain homogenates from control and lithiumtreated mice was performed using antibodies that recognize inactive GSK-3 (phosphorylated at serines 21 and 9 of GSK-3 $\alpha$ and $\beta$, respectively) and with antibodies that recognize GSK-3 ( $\alpha$ or $\beta$ isoforms) regardless of phosphorylation state. In good agreement with previous reports of lithium administration in vivo (30), an increase in phospho-GSK-3 was observed in brain homogenates of the lithium-treated mice (Figure 1C). Western blot analysis of tau phosphorylation at the GSK-3-dependent epitope PHF-1 (11) further confirmed decreased brain GSK-3 activity as a consequence of lithium administration (Figure 1C).

Upon completion of this 8-week lithium administration paradigm that results in decreased brain GSK-3 activity, mice were subjected to motor behavior testing. Since chronic lithium administration in mice is known to decrease body weight (35), and body weight can affect performance in many behavioral tests (36), we also analyzed in parallel a group of mice subjected to caloric restriction to match the $10 \%-15 \%$ body weight loss observed in the lithium-treated mice (Figure 1D).

We have previously reported that transgenic mice with decreased GSK-3 activity (Tet/DN-GSK-3 mice) perform poorly in striatumdependent motor tasks, such as the vertical pole test and the footprint test (34), while showing normal global motor activity in the open field test (34). Accordingly, we analyzed the lithium-treated mice in the vertical pole test and in the DigiGait apparatus, which measures footprint pattern and other parameters of walking regularity (Figure 1, E-H). In good agreement with the data from Tet/DN-GSK-3 mice, the vertical pole test revealed that lithium-treated mice spent twice the amount of time descending the pole compared with control mice $(9.75 \pm 0.78$ seconds versus $18.8 \pm 1.77$ seconds; $P<0.001)$, while the diet-subjected mice were indistinguishable from the control mice (Figure 1E). Lithium-treated mice also showed multiple gait abnormalities as measured with the DigiGait apparatus, such as increased variability in stride length (Figure 1F), increased variability in step angle (Figure $1 \mathrm{G}$ ), and stance asymmetry (Figure $1 \mathrm{H})$. These gait abnormalities are commonly found in patients and in mouse models of motor disorders such as Parkinson disease, Huntington disease, and amyotrophic lateral sclerosis (ALS) (37-39). Importantly, no gait abnormalities were observed in mice subjected to caloric restriction. Finally, in good agreement with the data from Tet/DN-GSK-3 mice, lithium-treated mice showed normal levels of global locomotion in the open field (data not shown). We can thus conclude that mice with serum lithium concentrations within the high therapeutic range for BD treatment show decreased brain GSK-3 activity accompanied by subtle motor side effects.

Neuronal apoptosis induced by chronic lithium administration. We then tested whether, as found in transgenic mice with decreased GSK-3 activity (34), the lithium administration paradigm that decreases GSK-3 activity and causes motor coordination deficits in wild-type mice also induces apoptosis in brain regions involved in motor control. To this end, we performed immunohistochemistry using an antibody that recognizes the active (cleaved) form of caspase- 3 on brain sections of mice that had been subjected to the 8-week administration paradigm and behavioral testing described above. As shown in Figure 2, A-G, most of the analyzed brain regions from lithiumtreated mice showed increased numbers of cleaved caspase-3-positive cells compared with controls. These include cortex, striatum, globus pallidus, hippocampus, and cerebellum (Figure 2, A-G). In contrast, amygdala, thalamus, and superior colliculus showed no significant difference (Figure $2 \mathrm{G}$ and data not shown). The most significant increases were observed in cortex and striatum, with 1.8- and 1.92-fold increases in the number of apoptotic neurons as compared with controls, respectively (Figure $2 \mathrm{G}$ ). A similar pattern of lithium-induced apoptosis across brain regions was found when the incidence of apoptosis was analyzed by TUNEL staining (Figure 2, $\mathrm{H}-\mathrm{L}$ ). It is worth noting that levels of lithium-induced apoptosis detected using this technique were much higher in the cerebellum and slightly higher in the cortex, striatum, globus pallidus, and hippocampus than those obtained with cleaved caspase-3 staining.

Finally, to investigate which cell types exhibit lithium-induced apoptosis, we performed double immunofluorescence with the cleaved caspase- 3 antibody and with markers of specific subpopulations. More precisely, we used antibodies directed at neuronal $(\mathrm{NeuN})$, astrocytic (glial fibrillary acidic protein [GFAP]), and microglial (Iba1) markers (Figure 2, M-S). Across the entire brain, the NeuN-positive subpopulation of caspase-3-positive cells was the only one that increased in lithium-treated mice. In fact, of the total cleaved caspase-3-positive cells in lithium-treated mice, 94\% were positive for NeuN (Figure 2S). Therefore, we can conclude that lithium-induced apoptosis essentially occurs in neurons.

Neuronal translocation of NFAT transcription factors by litbium. We next addressed the potential mechanisms by which chronic lithium and concomitant GSK-3 inhibition results in neuronal apoptosis. There is extensive literature indicating the dual role of GSK-3 inhibition in modulating apoptosis (see ref. 40 for a recent review). Briefly, it has been shown that GSK-3 inhibition prevents cell death induced by multiple apoptotic stimuli including growth factor withdrawal, DNA damage, glutamate toxicity, and many others (40). However, when apoptosis is triggered by activation of death domain-containing receptors such as Fas or the TNF receptor (i.e., when this is executed through the extrinsic pathway of apoptosis) (41), GSK-3 inhibition potentiates the apoptotic effect (40). This was first evidenced by the lithium-induced increase in TNF-mediated toxicity to mouse tumor cells (42). Subsequently, GSK-3 $\beta$-knockout mice were found to die embryonically due to hypersensitivity to TNF-induced apoptosis in the liver (43). This proapoptotic effect of GSK-3 inhibition was later extended to the other ligands of death domain-containing receptors such as TRAIL $(44,45)$. Finally, and with regard to neurons, apoptosis induced by activation of the Fas receptor was also found to be potentiated by several GSK-3 inhibitors including lithium (46).

We sought a possible link between GSK-3 inhibition and stimulation of the extrinsic pathway. Interestingly, it has been reported that GSK-3 inhibition promotes nuclear translocation of the nuclear factor of activated T cells c (NFATc) family of transcription factors in various cell types $(47,48)$, including primary cultured neurons (49). On the other hand, NFAT-mediated transcription is known to control expression of Fas ligand (FasL), the apoptosis initiator that activates Fas receptor (50). This led us to hypothesize the following mechanism by which chronic lithium administration may lead to neuronal apoptosis (Supplemental Figure 1; supplemental material available online with this article; 

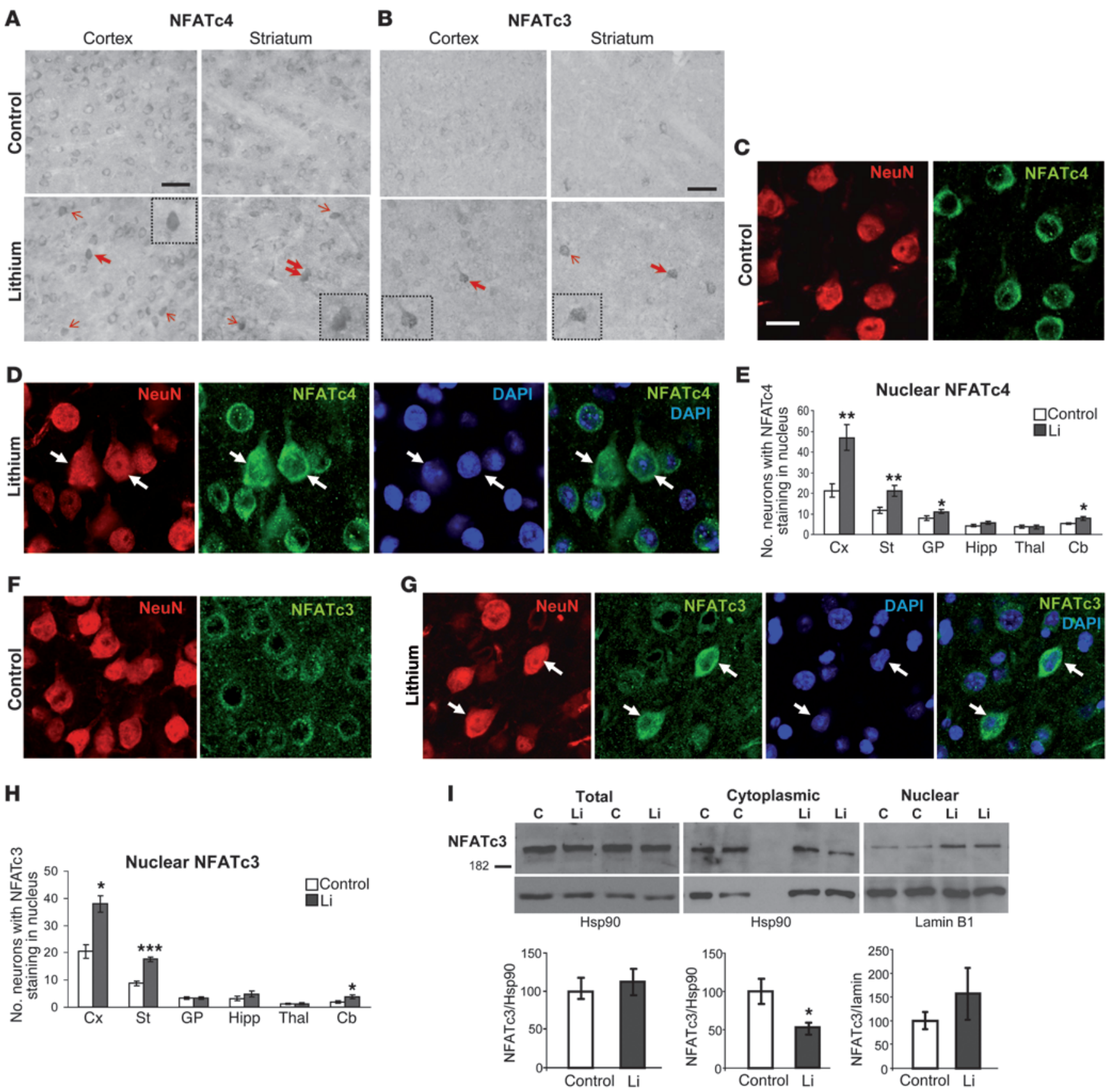

J

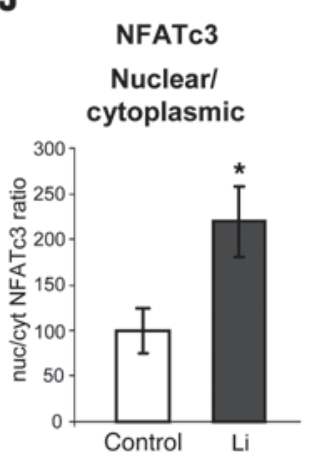

K
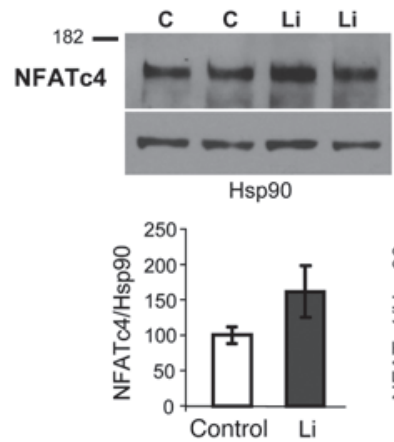

Cytoplasmic
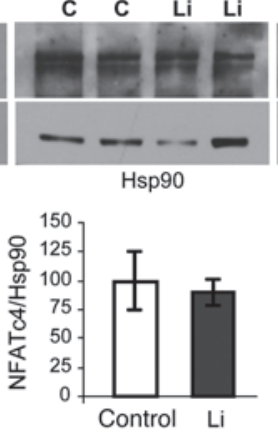

Nuclear
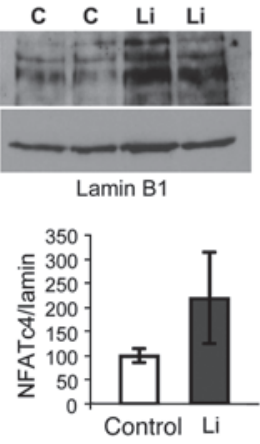

L

NFATc4

Nuclearl cytoplasmic

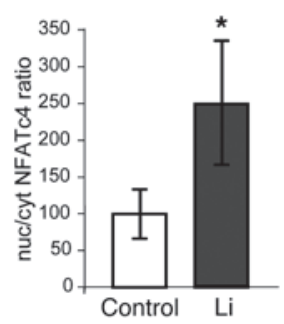




\section{Figure 3}

Increased nuclear localization of NFAT transcription factors in lithium-treated mice. (A) Representative images of NFATc4 immunohistochemistry in cortex and striatum of control and lithium-treated mice. Arrows indicate neurons with NFATc4 staining in the nucleus. (B) Representative images of NFATc3 immunohistochemistry in cortex and striatum of control and lithium-treated mice. Arrows indicate neurons with NFATc3 staining in the nucleus. Insets show higher magnifications of the cells marked with bold arrows. Scale bars in A and B: $100 \mu \mathrm{m}$. (C and D) Representative confocal microscope images showing a $1-\mu \mathrm{m}$-deep cortical area subjected to double immunofluorescence with NFATc4 antibody and NeuN antibody (to confirm neuronal identity) and DAPI counterstaining (to verify the nuclear localization) in control (C) and lithium-treated (D) mice. (E) Number of neurons exhibiting NFATc4 staining in the nucleus per section in regions analyzed ( $n=8$ per group). ( $\mathbf{F}$ and $\mathbf{G}$ ) Representative images of double immunofluorescence with NFATc3 and NeuN antibodies combined with DAPI nuclear counterstaining in cortex of control $(\mathbf{F})$ and lithium-treated (G) mice. Scale bar: $15 \mu \mathrm{m}(\mathbf{C}-\mathbf{G})$. (H) Number of neurons exhibiting NFATc3 staining in the nucleus per section in regions analyzed $(n=8$ per group). (I and K) Western blot detection of NFATc3 (I) and NAFTc4 (K) in total, cytoplasmic, and nuclear homogenates from cortex of control and lithium-treated mice ( $n=12$ per group). Hsp90 (total and cytoplasmic) and lamin B1 (nuclear) antibodies were assayed as loading control. Histograms represent quantification of total, cytoplasmic, and nuclear NFATc3 and NFATc4 corrected by the loading control. ( $\mathbf{J}$ and $\mathbf{L}$ ) Nuclear/cytoplasmic (nuc/cyt) ratio of NFATc3 (J) and NFATc4 (L). All histograms in I-L represent lithium values as a percentage compared with the control group. ${ }^{\star} P<0.05,{ }^{\star \star} P<0.01,{ }^{\star \star \star} P<0.001$.

doi:10.1172/JCI37873DS1). First, chronic lithium administration induces sustained GSK-3 inhibition, which, in turn, results in nuclear translocation of NFAT transcription factors and a subsequent increase in FasL production. Finally, the subsequent activation of the cognate receptor Fas initiates apoptosis via the extrinsic pathway. Accordingly, we designed a series of experiments to explore this hypothesis.

Since expression of NFATc-1, $-2,-3$, and -4 has been reported in brain based on in situ hybridization (51), we performed immunohistochemistry with antibodies against each of them in brain sections from control and lithium-treated mice. None of the tested NFATc2 antibodies yielded specific staining (data not shown). NFTAc1 antibodies recognized only a small subset of astrocytes in a small number of regions such as the globus pallidus and the hippocampus, with no obvious effect of lithium regarding nuclear translocation or total number of NFATc1-positive cells (data not shown). In good agreement with previous reports showing NFATc3 and NFATc4 expression in neurons $(49,52,53)$, both NFATc 3 and NFATc4 antibodies yielded a neuronal pattern in all brain regions analyzed (Figure $3, \mathrm{~A}$ and $\mathrm{B}$ ).

The specificity of the employed NFATc3 and NFATc4 antibodies was confirmed by staining brain sections from NFATc3- and NFATc4-knockout mice (Supplemental Figure 2), and the neuronal identity of NFATc3- and NFATc4-positive cells was confirmed by double immunofluorescence with the neuronal marker NeuN (Figure 3, C-G). In untreated mice, both NFATc3 and NFATc4 antibodies yielded only cytoplasmic staining in the vast majority of neurons (control panels in Figure 3, A and B, and Figure 3, C and F), with the number of NFATc4-positive neurons being higher than that of NFATc3-positive neurons (compare control panels in Figure 3A with control panels in Figure 3B). Interestingly, as anticipated in our working hypothesis, lithium treatment resulted in a significant increase in the number of neurons in which NFATc4 and NFATc3 staining was also present in the nucleus (see lithium panels in Figure 3, A, B, D, E, G, and H). Nuclear localization was verified by confocal microscope analysis of brain sections subjected to NFAT/NeuN double immunofluorescence and DAPI-nuclear counterstaining (Figure 3, $\mathrm{D}$ and $\mathrm{G}$ ). These data are in good agreement with a previous report of increased nuclear levels of NFATc4 as a consequence of decreased GSK-3 activity in cultured neurons (49). Importantly, except for the hippocampus, there is a good correlation between the brain regions that show increased neuronal apoptosis and those showing increased nuclear staining of the NFAT transcription factors. Such is the case for cortex, striatum, globus pallidus, and cerebellum. Accordingly, the amygdala, thalamus, and superior colliculus showed neither increases in apoptosis nor nuclear translocation of NFAT transcription factors (Figure 3, E and $\mathrm{H}$, and data not shown).

Apart from an increase in the number of neurons with nuclear NFATc 3 and NFATc4, the above-described immunostainings (Figure $3, A-G$ ) may also show an increase in the overall levels of both transcription factors as a result of chronic lithium treatment. To further confirm the increased nuclear translocation of NFATc3 and NFATc4 in response to lithium and to properly address the possible overall increase, we performed Western blot analysis with nuclear and cytoplasmic fractions as well as with total homogenates from control and lithium-treated mice. As shown in Figure 3I, total NFATc3 levels were not increased in brain of lithium -treated mice. Interestingly, NFATc3 levels were significantly decreased in the cytoplasmic fraction of lithium-treated mice. This, together with a trend toward increased NFATc3 levels in the nuclear fraction, resulted in a significant increase in NFATc3 nuclear/cytoplasmic ratio as a consequence of lithium administration (Figure 3J). In the case of NFATc4 and in good agreement with the above-mentioned observation in immunohistochemistry and immunofluorescence experiments, Western blot analysis of total homogenates showed a trend toward increased overall levels in lithium-treated mice (Figure 3K). Interestingly, this effect of lithium fits well with the reported role of GSK-3 in decreasing NFATc4 stability by promoting its ubiquitination (54). Despite the apparent increase in NFATc4 in total homogenates, we still observed slightly lower levels of NFATc4 in the cytosolic fraction of lithium-treated mice. This, together with the increased levels observed in the nuclear fraction of lithium-treated mice, led to a significant increase in NFATc4 nuclear/cytoplasmic ratio as a consequence of lithium administration (Figure 3L). In summary, the Western blot analysis of NFATc3 and NFATc4 in total homogenates showed no change in the overall NFATc3 level and a tendency toward increased NFATc4 levels in response to chronic lithium. More importantly, the analysis of nuclear and cytoplasmic fractions confirmed the lithium-induced increase in NFATc3 and NFATc4 nuclear translocation observed by immunohistological methods, with the increased difference between control and lithium-treated mice likely due to enrichment of the sample following nuclear isolation.

Increased FasL after chronic lithium correlates with GSK-3 inbibition and nuclear NFAT translocation. To explore whether the increased nuclear translocation of NFAT transcription factors resulted in increased FasL in brain of lithium-treated mice, we performed Western blot and immunohistochemical studies. Western blot revealed an increase in levels of both full-length FasL and the soluble shed form (sFasL) in the striatum of lithium-treated mice (Figure 4, A and B). In the cortex, the full-length form was also increased, by $42 \%$, in lithium-treated mice $(n=5, P<0.05)$, while no significant changes were detected in the shed form (data not shown). In good agreement with these findings, FasL 
A

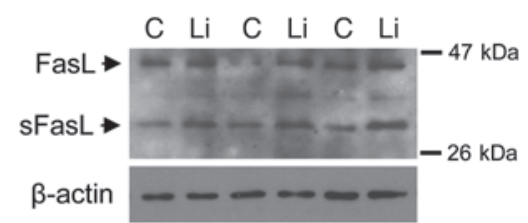

B

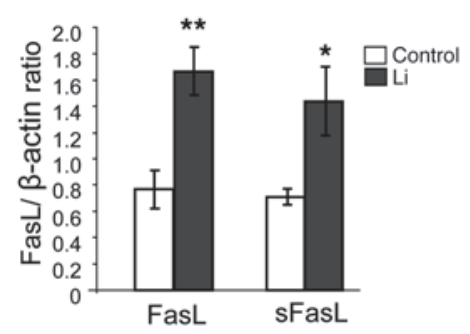

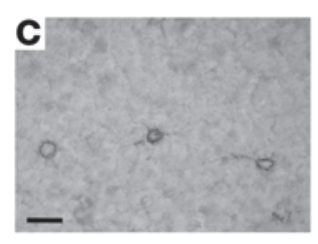

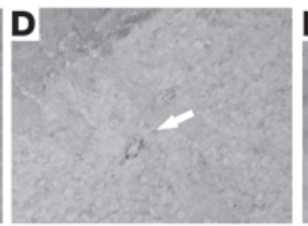

$\mathbf{F}$

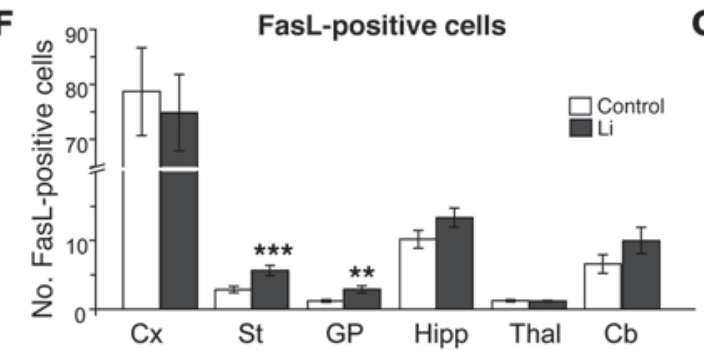

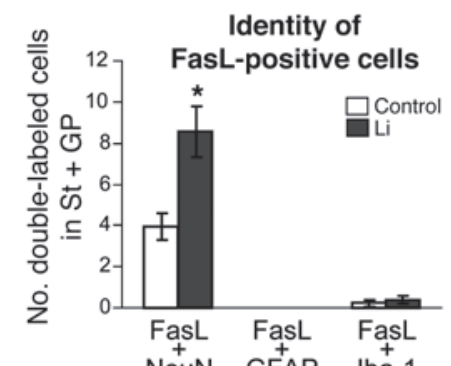
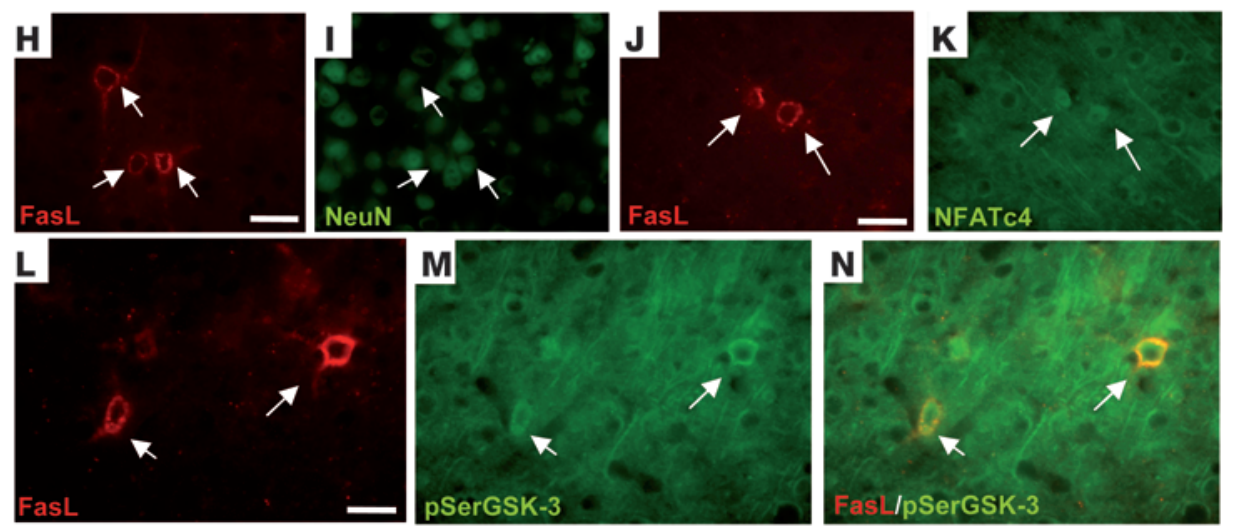

\section{Figure 4}

Level of FasL and number of FasLpositive neurons are increased in chronic lithium-treated mice. (A and B) Western blot detection (A) and quantification (B) of the full-length and shed soluble form of FasL (FasL and SFasL, respectively) in striatal cytoplasmic fraction of control and lithium-treated mice ( $n=5$ per group). (C-E) FasL immunohistochemistry in brain sections from lithium-treated mice. Micrographs show positive cells in cortex (C), striatum (D), and globus pallidus (E). Scale bars: $40 \mu \mathrm{m}$ (C) and $30 \mu \mathrm{m}$ (D and E). (F) Histogram showing quantification of FasL-immunoreactive cells in control and lithiumtreated mice in regions analyzed ( $n=16$ per group). (G) Histogram showing quantification of double staining with FasL antibody and markers of specific cell types $(n=8$ per group). (H-N) Representative images of double-labeling immunofluorescence in striatum of lithium-treated mice: with anti-FasL (H) and anti-NeuN (I) antibodies; with anti-FasL (J) and anti-NFATc4 (K) antibodies; and with anti-FasL (L) and anti-pSer21/9-GSK-3a/ $\beta$ antibodies (M). $\mathbf{N}$ is a merge of the images in $\mathbf{L}$ and $\mathbf{M}$. Scale bars: $20 \mu \mathrm{m}(\mathbf{H}$ and I); $20 \mu \mathrm{m}$ ( $\mathbf{J}$ and $\mathbf{K}) ; 10 \mu \mathrm{m}(\mathbf{L}-\mathbf{N})$. ${ }^{*} P<0.05,{ }^{* *} P<0.005,{ }^{* \star *} P<0.002$. immunohistochemistry revealed a significant increase in the number of FasL-positive cells in the striatum and globus pallidus of lithium-treated mice (Figure 4, C-F). A tendency toward increased numbers of FasL-positive cells was also observed in the cerebellum of treated mice, though this effect did not reach statistical significance (Figure 4F). The cortex, despite showing increased FasL levels by Western blot, showed no difference in the number of FasL-positive cells. This may be due to the fact that this brain structure, apart from showing the highest number of positive cells (Figure 4F), also contained the cells with the strongest labeling compared with any other brain region (Figure 4C). It therefore seems that the cortical cells susceptible to an increase in FasL levels upon lithium-induced NFAT translocation are already above the threshold for detection by immunohistochemistry in untreated mice.

In good agreement with previous reports $(52,55)$, the vast majority of brain FasL-immunoreactive cells appeared to be neurons based on their morphology (Figure 4, C-E). To confirm this observation and further explore the role of GSK-3 inhibition and subsequent NFAT nuclear translocation in the lithium-induced increase in FasLpositive cells, we performed double labeling immunofluorescence studies on striatal sections of lithium-treated mice. As shown in Figure 4, G-I, 95\% of the FasL-positive cells were confirmed to be neurons by double labeling with the neuronal marker NeuN. Furthermore, striatal FasL-positive neurons coincide with those showing nuclear staining of NFAT (Figure 4, J and K) and were also detected with an antibody that recognizes phospho-GSK-3 (pSer21/9-GSK-3, Figure 4, L-N). The fact that GSK-3 inactivation, NFAT nuclear translocation, and FasL immunostaining all coincide in the same subset of neurons strongly suggests that these events are functionally related and support our mechanistic hypothesis.

Blockade of NFAT nuclear translocation by cyclosporin A prevents lithium-induced motor deficits and-apoptosis. To explore whether the abovedescribed NFAT/FasL changes in lithium-treated mice are in fact responsible for the lithium-induced neuronal apoptosis and maybe also for the motor deficits, we decided to perform similar experi- 
A
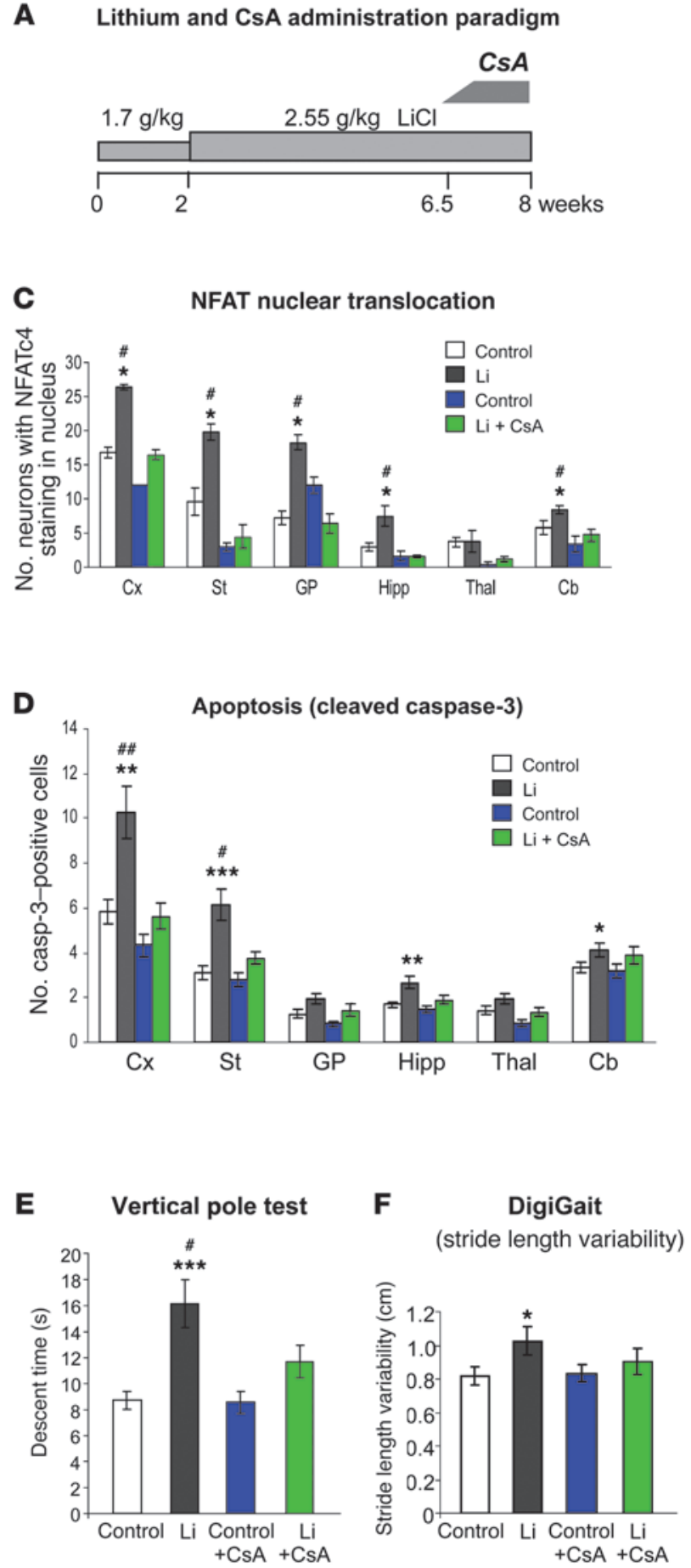

B
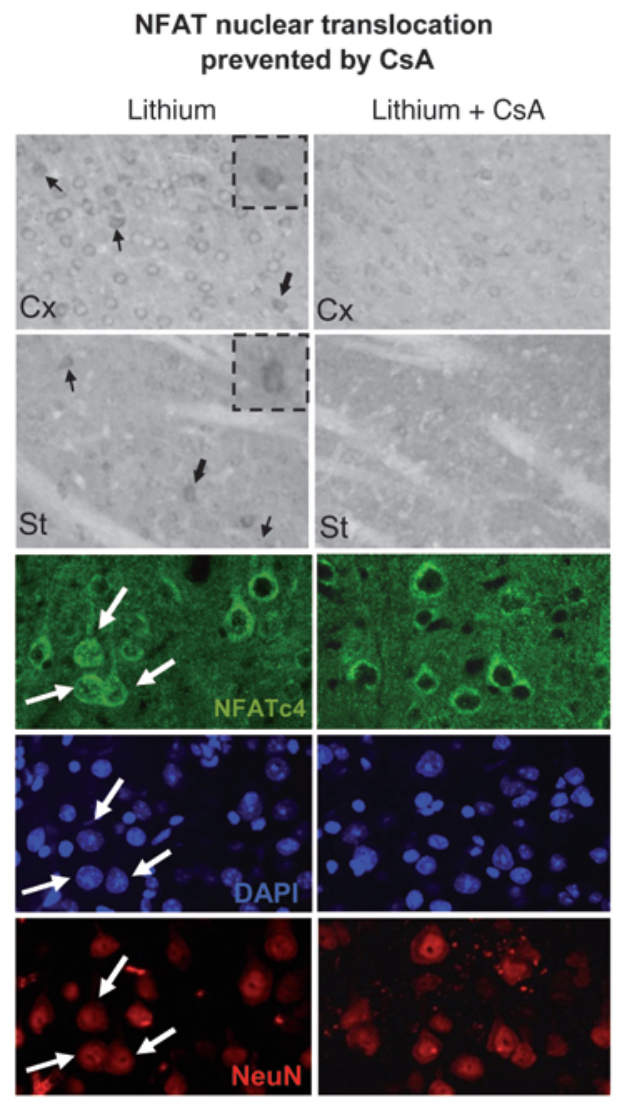

\section{Figure 5}

CsA administration impedes NFAT nuclear translocation and prevents chronic lithium-induced apoptosis and motor deficits. (A) Diagram showing lithium and CsA administration protocol in mice. (B) Immunohistological detection of NFATc4. Upper panels show representative immunohistochemistry images in cortex and striatum. Lower panels show confocal microscope images $(1 \mu \mathrm{m})$ of double immunofluorescence with NeuN together with DAPI nuclear counterstaining in cortex. Left and right panels correspond to lithium- and lithium plus CsA-treated mice, respectively. Arrows indicate neurons with NFATc4 staining in the nucleus, and insets in the upper panels show higher magnifications of the cells marked by bold arrows. Scale bars: $100 \mu \mathrm{m}$ (upper panels) and $15 \mu \mathrm{m}$ (lower panels). (C) Number of neurons exhibiting NFATc4 staining in the nucleus per section in regions analyzed ( $n=4$ per group). (D) Number of cleaved caspase-3-positive cells per 30- $\mu \mathrm{m}$ sagittal section in regions analyzed (control, $n=19$; lithium, $n=19$; control + CsA, $n=12$; lithium + CsA, $n=12$ ). (E) Descent time in vertical pole test (control, $n=20$; lithium, $n=17$; control + CsA, $n=19$; lithium + CsA, $n=20)$. ( $\mathbf{F}-\mathbf{H})$ Gait analysis. Stride length variability $(\mathbf{F})$, step angle variability $(\mathbf{G})$, and stance asymmetry $(\mathbf{H})$ in footprint test as measured by DigiGait system (control, $n=15$; lithium, $n=12$; control + CsA, $n=16$; lithium + CsA, $n=16$ ). ${ }^{\star} P<0.05,{ }^{* *} P<0.01,{ }^{* *} P<0.001$ versus control; $\# P<0.05$ versus lithium + CsA. 


\section{A Lithium administration to wt and Ipr mice}

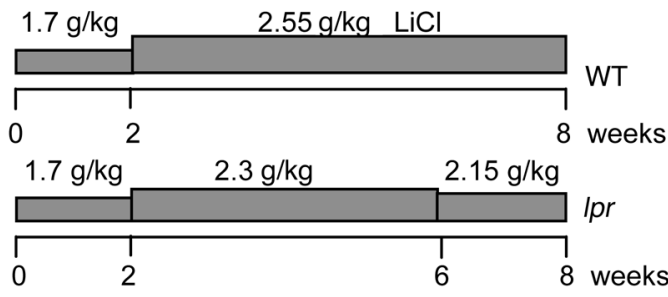

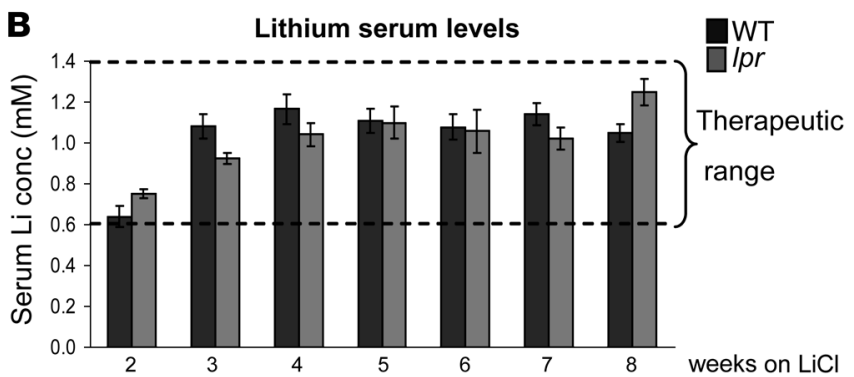

C

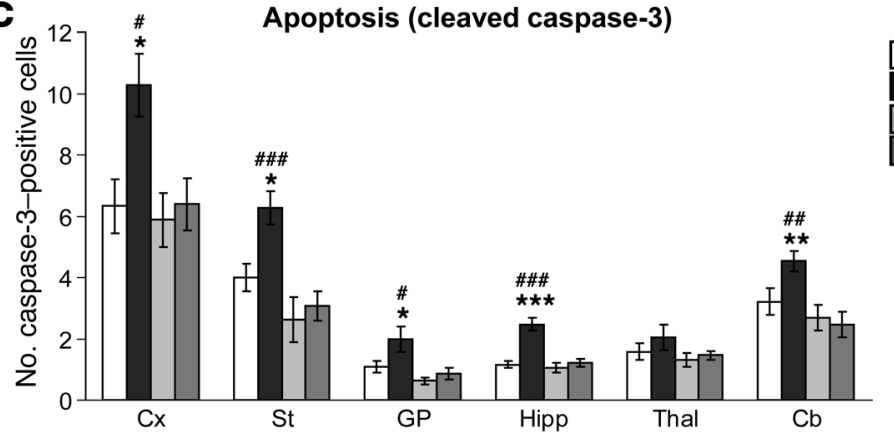

D

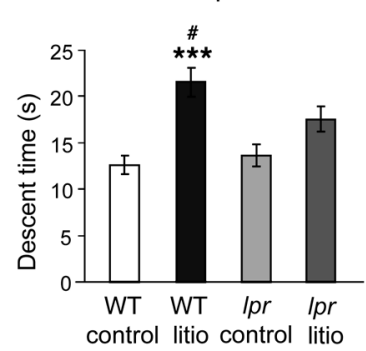

E

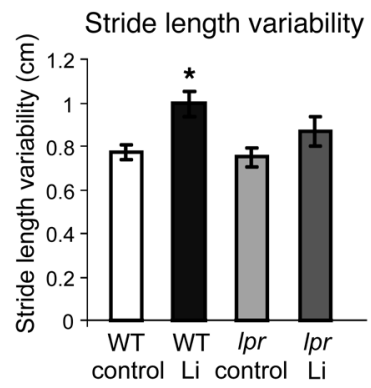

$\mathbf{F}$

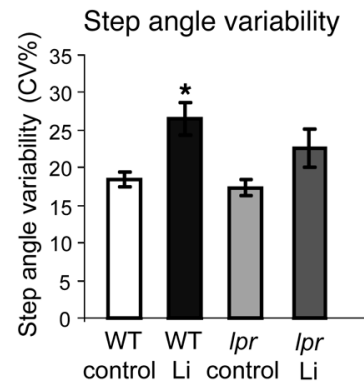

G Stance asymmetry

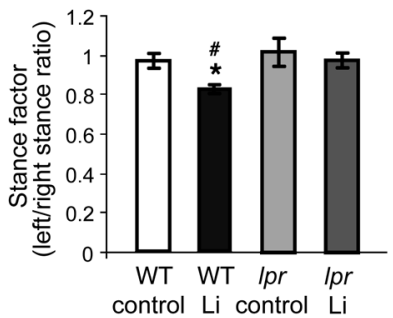

Figure 6

Fas-deficient (Ipr) mice are resistant to chronic lithium-induced neuronal apoptosis and do not show the motor coordination deficits observed in wild-type mice. (A) Diagram showing lithium administration protocol to wild-type and Ipr mice. (B) Lithium plasma levels over the 8-week treatment in wild-type and Ipr mice (WT, $n=22 ; / p r, n=13$ ). (C) Number of cleaved caspase-3-positive cells per 30- $\mu \mathrm{m}$ sagittal section in regions analyzed in wild-type and Ipr mice (WT control, $n=10$; WT lithium, $n=9$; Ipr control, $n=7$; Ipr lithium, $n=7$ ). (D) Descent time in vertical pole test (WT control, $n=20$; WT lithium, $n=17$; Ipr control, $n=19$; Ipr lithium, $n=20$ ). (E-G) Stride length variability, step angle variability, and stance asymmetry in footprint test measured by DigiGait system in control or lithium-treated WT and Ipr mice (WT control, $n=27$; WT lithium, $n=21$; Ipr control, $n=16$; Ipr lithium, $n=11) .{ }^{*} P<0.05,{ }^{* \star} P<0.01,{ }^{* *} P<0.001$, versus WT control; ${ }^{*} P<0.05,{ }^{\# \#} P<0.01$, \#\#\# $P<0.001$ versus Ipr lithium.

ments with lithium-treated mice in which we interfered with NFAT and/or FasL signaling (see Supplemental Figure 1C). Regarding NFAT, the effect of GSK-3 on cytoplasmic/nuclear shuttling of NFAT transcription factors is balanced by calcineurin activity. Briefly, GSK-3 phosphorylates conserved NFAT serine residues necessary for NFAT nuclear export and therefore promotes NFAT nuclear exit (47). On the contrary, calcineurin dephosphorylates those conserved serine residues, thus favoring NFAT nuclear translocation, which can be prevented with the calcineurin inhibitor cyclosporin A (CsA) $(48,56)$. We thus reasoned that CsA administration during the last days of the lithium treatment paradigm could be used to prevent the lithium-induced nuclear translocation of NFAT transcription factors. If this nuclear NFAT translocation is indeed required for the neurotoxicity and motor behavioral consequences of lithium, these should be diminished by CsA administration. Accordingly, we estab- lished a protocol of CsA administration in drinking water during the last 1.5 weeks of lithium treatment (Figure $5 \mathrm{~A}$ ) that fully prevented the above-described lithium-induced nuclear translocation of NFAT transcription factors, as evidenced by immunohistochemistry and confocal analysis of immunofluorescence with DAPI nuclear counterstaining (Figure 5, B and C).

We then analyzed the effect of CsA administration on apoptosis by immunohistochemical detection of cleaved caspase-3. As shown in Figure 5D, CsA administration did not affect the incidence of apoptosis in control mice. More importantly, the lithium-induced increase in apoptosis described previously was no longer detected in any brain region of CsA-treated mice.

Finally, we also analyzed the effect of CsA administration on the previously described lithium-induced motor deficits. As shown in Figure 5E, CsA administration significantly improved the perfor- 
mance of lithium-treated mice in the vertical pole test, whereas no effect was observed on the performance of control mice. Similarly, while deficits in walking pattern observed with the DigiGait apparatus in lithium-treated mice (increased stride length variability, increased step angle variability, and stance asymmetry) were corrected by CsA treatment, no effect was observed in control mice (Figure 5, F-H). These results, together with the data indicating apoptosis prevention by CsA treatment, strongly suggest that NFAT nuclear translocation contributes to lithium-induced neuronal apoptosis and motor deficits.

Fas-deficient mice are resistant to the neuronal apoptosis and motor side effects of chronic lithium administration. If our working hypothesis is true, the increased incidence of apoptosis in lithium-treated mice should eventually be due to the activation of the death receptor Fas. To investigate whether FasL signaling is also relevant to the observed neurotoxic effects of lithium, we analyzed apoptosis and motor behavior after chronic lithium administration in Fas receptor-deficient mice (lpr mice; ref. 57). In these mice, the lithium dosing paradigm described for wild-type mice (Figure 1A) resulted in serum lithium concentrations slightly greater than $1.5 \mathrm{mM}$ by week 4 (data not shown), thus exceeding the therapeutic window in humans. This is attributable to the compromised renal function of $l p r$ mice (58). For this reason, we slightly modified the dosing paradigm to achieve lithium plasma levels equivalent to those obtained in wild-type mice (Figure 6, A and B).

Using cleaved caspase- 3 immunostaining, we analyzed the incidence of apoptosis in wild-type and lpr mice following the 8-week dosing paradigm. Interestingly, the increases in apoptosis observed in the cortex, striatum, globus pallidus, hippocampus, and cerebellum of lithium-treated wild-type mice were absent in lithium-treated lpr mice (Figure 6C). These findings thus demonstrate that neuronal apoptosis induced by chronic lithium is mediated by the Fas receptor.

We then decided to compare the motor effects of lithium in lpr and wild-type mice. We first verified that untreated $l p r$ mice did not show any confounding signs of altered global activity or anxiety. For this, we performed the open field test and found that global locomotor activity and the time in center versus periphery shown by lpr mice were indistinguishable from those observed in wild-type mice (data not shown). Interestingly, the lithium-induced motor coordination deficit (detected in the vertical pole test; Figure 6D) and the gait abnormalities (detected with the DigiGait apparatus; Figure 6, E-G) observed in wild-type mice were absent in lithium-treated $l p r$ mice. These results, apart from demonstrating a role of Fas signaling in lithium-induced neurotoxicity, strongly suggest that neuronal loss contributes to the motor side effects of chronic lithium administration.

\section{Discussion}

By establishing a regimen of chronic lithium administration resulting in lithium plasma levels within the therapeutic range for $\mathrm{BD}$, we have reproduced in mice the common neurological side effects of lithium therapy, and we have used this model to demonstrate for the first time to our knowledge that chronic lithium administration in the upper range of therapeutic doses induces neuronal apoptosis in multiple brain regions, notably the striatum and other basal ganglia structures. Furthermore, we describe the following mechanism of lithium-induced neurotoxicity: GSK-3 inhibition elicits an increase in nuclear translocation of NFAT transcription factors, leading to increased FasL levels, which in turn facilitate apoptosis in the same or neighboring neurons through activation of Fas death receptor.
Finally, we demonstrate that NFAT/Fas signaling mediates both lithium-induced neuronal apoptosis and lithium-induced motor deficits, as these are absent when NFAT nuclear translocation is prevented by CsA administration or when the experiments are performed on Fas-deficient lpr mice.

The precise molecular mechanisms through which lithium exerts its unwanted neurological side effects are poorly understood. Here we show that lithium-mediated inhibition of GSK-3 plays a key role in the side effects of lithium therapy. In addition to GSK-3, lithium acts as an inhibitor of numerous other enzymes, including inositol monophosphatase, inositol polyphosphate 1-phosphatase, fructose 1,6-bisphosphatase, bisphosphate nucleotidase, and phosphoglucomutase (59). However, our previous findings of similar motor coordination deficits and neuronal apoptosis in transgenic mice with neuronal expression of a dominant-negative form of GSK-3 (34) confirm that the neurotoxic effects of lithium described here are mediated through GSK-3 inhibition. Besides, several lithium-induced behaviors have been shown to be GSK-3-mediated, since they are also observed in mice lacking one copy of the gene encoding GSK-3 $\beta$ (60).

Taken together with the apoptotic phenotypes of GSK-3 $\beta$ knockout (43) and dominant-negative GSK-3-transgenic (34) mice, our findings with chronic lithium administration provide further in vivo evidence of a dual role for GSK-3 inhibition in the regulation of apoptosis (40). A large body of literature describes the neuroprotective effects of lithium (61), whereby lithium counteracts the effects of multiple stimuli that induce neuronal apoptosis through the intrinsic pathway (40). Lithium administration, however, has also been shown in primary cultured neurons to facilitate apoptosis mediated by the extrinsic pathway (i.e., with activation of death receptors such as Fas) (46). Our study therefore further elaborates, in an in vivo context, on the mechanisms that favor apoptosis through the extrinsic pathway.

There is a good correlation between brain regions affected in the lithium administration model described here and the Tet/DN-GSK-3 mouse model. In both cases, the striatum appears most vulnerable to lithium-induced toxicity, showing the greatest increase in the number of apoptotic neurons (34). Similarly, increases in neuronal apoptosis are observed in the cortex in both models. In the lithium treatment paradigm, however, we have also detected vulnerable neurons in globus pallidus and cerebellum that could not be detected in the dominant-negative GSK-3 transgenic mice due to the restriction of transgene expression to forebrain neurons (34).

That the striatum is one of the most affected brain regions following chronic GSK-3 inhibition fits well with the observed neurological motor side effects and is supported by previous reports of GSK-3 mediation of dopamine transmission in striatal neurons (62). More precisely, lithium has been shown to inhibit striatal GSK-3 activity through increased Akt-mediated phosphorylation (62) in part via a positive feed-forward loop involving protein phosphatase-1 (32). Furthermore, lithium can also disrupt the complex that $\beta$-arrestin 2 , protein phosphatase-2A, and Akt form with the dopamine D2 receptor (31) that is mainly located in the striatum. Together, all these findings support a preferential impact of GSK-3 inhibition on striatal physiology.

NFAT has been proposed to participate in striatal neuronal apoptosis induced by methamphetamine (52), and NFAT-mediated apoptosis has been reported in other tissues and cell types (63). Furthermore, deafferentiation-induced neuronal loss in the cochlear 
nucleus has also recently been proposed to be mediated not only by NFATc 4 activation but also by subsequent FasL-mediated apoptosis (64), thus mirroring our mechanistic findings concerning lithiuminduced apoptosis. It should be noted, however, that apart from the NFAT/Fas-mediated mechanism described here, a distinct and compatible mechanism by which GSK-3 inhibition facilitates apoptosis through the extrinsic pathway has been recently reported. Specifically, a death receptor-associated antiapoptotic protein complex containing GSK3, DDX3, and cellular inhibitor of apoptosis protein-1 (cIAP-1) has been characterized in HeLa and in MDA-MB-231 human breast cancer cells, with inhibition of GSK-3 facilitating disassembly of the complex and execution of apoptosis (65).

The mechanism of lithium-induced neurotoxicity described here has important implications for the management of BD and may aid in the development of combined therapies designed to prevent acute lithium intoxication and ameliorate the neurological side effects associated with therapeutic doses. Specifically, pharmacological interventions that counteract the increased NFAT nuclear translocation or the FasL/Fas signaling cascade are suitable candidates to combat neurological side effects. One such candidate is CsA, in view of its attenuation of lithium-induced neuronal apoptosis and motor side effects in mice, as reported here. Importantly however, the clinical use of CsA and other calcineurin inhibitors (56) to counteract adverse effects of lithium can be limited by their associated nephrotoxicity (66).

Regarding the neuroprotective effects of CsA and its normalization of motor behavior, the question remains as to whether new neurons replace those that die during the 6.5 weeks of lithium treatment prior to CsA administration. In view of the recent report of mice with deletion of GSK-3 in the developing nervous system (67), and assuming a parallel between the effect of GSK-3 deletion in embryonic and adult neurogenesis, replacement by new neurons seems unlikely. Briefly, GSK-3 deletion in mice results in increased proliferation of embryonic neural progenitors but decreased generation of intermediate neural progenitors and postmitotic neurons (67). It is therefore more likely that, after CsA administration, the remaining neurons attain a less-altered intracellular physiology, leading to a recovery of function in the affected neural circuit. We have previously reported a similar scenario in a conditional mouse model of Huntington disease (68). Mice that constitutively express mutant huntingtin from birth show both motor deficits and a $12 \%$ loss of striatal neurons by 17 months. However, if mutant huntingtin expression is halted at that age, motor function is normalized within 5 months. Stereological analysis revealed that cessation of mutant huntingtin expression between 17 and 22 months of age still results in a $20 \%$ decrease in the number of striatal neurons at 22 months (versus the $44 \%$ decrease observed in mice with continued mutant huntingtin expression) (68). In conclusion, once striatal neuron physiology is no longer compromised by mutant huntingtin expression, the remaining $80 \%$ of striatal neurons are sufficient for functional normalization of the affected brain circuit. Similarly, in the present study it is possible that recovery of neuronal function of the remaining neurons after 1.5 weeks of administration of CsA rather than neuronal replacement is responsible for the recovery of circuit function.

Finally, the mechanism of GSK-3 inhibition-mediated toxicity reported herein and the underlying new opportunities to counteract it may also have implications for AD and any other conditions such as ALS and diabetes for which lithium or other GSK-3 inhibitor therapies have been proposed $(69,70)$. Regarding the ongoing clinical trials of lithium for ALS (71), it will be of particular interest to see whether the potential observed in the initial study (70) is confirmed, given the well-known role of Fas signaling in mediating apoptotic death of ALS spinal motoneurons (72). In this regard, a recent study did not identify any therapeutic benefit of chronic lithium treatment with respect to disease onset, progression of neurological symptoms, or survival duration in a mouse model (73). Interestingly, and in good agreement with our study, the study found evidence for early onset of low-grade neurological symptoms and signs of less-effective body weight maintenance (73). Regarding lithium clinical trials for $\operatorname{AD}(19,23,74)$, frequent extrapyramidal side effects were already detected in a pilot study (22), and recent study of the feasibility and tolerability of lithium therapy in $\mathrm{AD}$ patients reports high rates of discontinuation due to the high incidence of lithium toxicity in the elderly (19).

In summary, our results may help to correctly interpret those of the multiple ongoing lithium clinical trials and may enable not only the development of new combined therapies to counteract the drawbacks of lithium treatment for mood disorders but also the extension of the potential of lithium (and other more selective GSK-3 inhibitors) to AD and other chronic conditions for which GSK-3 inhibition therapy has been proposed.

\section{Methods}

Animals. Wild-type C57BL/6 mice were obtained from Harlan or The Jackson Laboratory. Fas-deficient lpr mice (C57BL/6 background) were obtained from The Jackson Laboratory and subsequently bred in our facilities. NFATc3knockout mice (75) were obtained from Francesca Granucci (University of Milano-Bicocca, Milan, Italy). NFATc4-knockout mice (76) were obtained from Jeffrey Molkentin (Cincinnati Children's Hospital Medical Center, Cincinnati, Ohio, USA). All mice were housed at the CBM"SO" animal facility. Mice were housed 4 per cage with food and water available ad libitum and maintained in a temperature-controlled environment on a 12-hour light/12-hour dark cycle with light onset at 07:00. All experiments were performed under a protocol approved by the ethical committee of CSIC.

Lithium administration. Two-month-old wild-type C57BL/6 mice were fed chow containing $1.7 \mathrm{~g} \mathrm{LiCl} / \mathrm{kg}$ (Harlan Teklad) for 2 weeks, followed by a diet containing $2.55 \mathrm{~g} \mathrm{LiCl} / \mathrm{kg}$ for 6 weeks. Control mice were fed lithium-free chow under parallel conditions. Blood lithium levels were analyzed weekly by inductively coupled plasma mass spectrometry (ICP-MS). Two-month-old lpr mice (C57BL/6 background) were also fed chow containing $1.7 \mathrm{~g} \mathrm{LiCl} / \mathrm{kg}$ for 2 weeks, followed by a diet containing $2.3 \mathrm{~g} \mathrm{LiCl} / \mathrm{kg}$ for 4 weeks and $2.15 \mathrm{~g} \mathrm{LiCl} / \mathrm{kg}$ for the final 2 weeks. To prevent hyponatremia, water and a $\mathrm{NaCl}$ solution $(450 \mathrm{mM})$ were available to all animals.

Diet. Lithium-treated mice lost $10 \%-15 \%$ of their body weight over the 8 -week treatment described above. To control for lithium-induced decreases in body weight, a weight-matched group was maintained by means of caloric restriction similar to that described previously $(77,78)$. Briefly, we first measured the daily amount of chow taken by an equivalent group of untreated mice for 1 week. The following week, they received $90 \%$ of that amount per day, and the rest of the time up to 8 weeks the amount was restricted to $70 \%$ per day.

Cs $A$ administration. Wild-type C57BL/ 6 mice were treated with lithiumcontaining or control chow according to the regimen described above. After 6.5 weeks, each animal group was split in 2 subgroups, one treated with CsA (Sandimmume Neoral, Novartis) in saccharine-flavored drinking water and the other receiving just saccharine-flavored water. In view of the reported dose of CsA tolerated by mice (79), CsA concentration in drinking water was calculated to deliver a dose of $8 \mathrm{mg} / \mathrm{kg} / \mathrm{d}$ during the 2 first days. Then it was increased to deliver $16 \mathrm{mg} / \mathrm{kg} / \mathrm{d}$ for 2 more days and finally maintained at $24 \mathrm{mg} / \mathrm{kg} / \mathrm{d}$ until the end of treatment. 
Antibodies. For immunochemistry and immunofluorescence experiments, the following antibodies were used: pSer21/9-GSK-3 $\alpha / \beta$ (Cell Signaling Technology), cleaved caspase-3 (Cell Signaling Technology), NeuN (Chemicon), GFAP (Promega), Iba-1 (WAKO), NFATc1 (7A6 from AbCam and K-18 from Santa Cruz Biotechnology Inc.), NFATc2 (G1-D10 and 4G6-G5 from Santa Cruz Biotechnology Inc.), NFATc3 (M-75 rabbit and A-17 goat from Santa Cruz Biotechnology Inc.), NFATc4 (H-74 and I-8 from Santa Cruz Biotechnology Inc.), and FasL (N-20 goat from Santa Cruz Biotechnology Inc.). The specificity of NFATc3 A-17, NFATc4 I-8, and FasL N-20 antibodies was verified by using the corresponding blocking peptides, sc23814-P, sc-32989-P, and sc-834-P respectively. For Western blot analysis, the following antibodies were used: pSer21/9-GSK-3 $\alpha / \beta$ (Cell Signaling Technology), GSK-3 $\alpha / \beta$ (BD Biosciences - Transduction Laboratories), PHF-1 (a gift of Peter Davies, Albert Einstein College of Medicine, New York, New York, USA), $\beta$-actin (Sigma-Aldrich), NFATc3 A-17 goat (Santa Cruz Biotechnology Inc.), NFATc4 ab3447 (Abcam), Hsp90 Ac88 (Stressgen), lamin B1 (Santa Cruz Biotechnology Inc.), and FasL (Calbiochem).

Western blot analysis. Brains were quickly dissected on an ice-cold plate. For analysis of pSer21/9-GSK-3 and phospho-tau, whole extracts were prepared by homogenizing the brain areas from right hemisphere in ice-cold extraction buffer consisting of $20 \mathrm{mM}$ HEPES pH 7.4, $100 \mathrm{mM} \mathrm{NaCl}, 20 \mathrm{mM} \mathrm{NaF}, 1 \%$ Triton X-100, $1 \mathrm{mM}$ sodium orthovanadate, $1 \mu \mathrm{M}$ okadaic acid, $5 \mathrm{mM}$ sodium pyrophosphate, $30 \mathrm{mM} \beta$-glycerophosphate, $5 \mathrm{mM}$ EDTA, and protease inhibitors $(2 \mathrm{mM}$ PMSF, $10 \mu \mathrm{g} / \mathrm{ml}$ aprotinin, $10 \mu \mathrm{g} / \mathrm{ml}$ leupeptin, and $10 \mu \mathrm{g} / \mathrm{ml}$ pepstatin). Samples were homogenized and centrifuged at $15,000 \mathrm{~g}$ for 20 minutes at $4{ }^{\circ} \mathrm{C}$. The resulting supernatant was collected and protein content determined by Bradford assay. Sample fractionation was performed for analysis of FasL, given its presence in microvesicles enriched in cytoplasmic fraction $(80,81)$. Briefly, frozen brain tissue was homogenized with a tissue grinder in a buffer containing $250 \mathrm{mM}$ sucrose, $20 \mathrm{mM}$ HEPES (pH 7.4), $10 \mathrm{mM} \mathrm{KCl}, 1.5 \mathrm{mM} \mathrm{MgCl}_{2}$, 1 mM EDTA, 1 mM EGTA, 1 mM DTT, 1 mM sodium orthovanadate, $1 \mu \mathrm{M}$ okadaic acid, $5 \mathrm{mM}$ sodium pyrophosphate, $30 \mathrm{mM} \beta$-glycerophosphate, and protease inhibitor cocktail (Roche). After being left on ice for 20 minutes, samples were centrifuged at $720 \mathrm{~g}$ for $5 \mathrm{~min}$ utes. The nuclear pellet (P1) was washed with the same buffer. Supernatants (S1) were centrifuged at $6,000 \mathrm{~g}$ for 20 minutes to separate the mitochondrial fraction (P2). The remaining sample (S2) was then ultracentrifuged at $100,000 \mathrm{~g}$ for 1 hour to separate membranes (P3). This pellet was resuspended in the same buffer and ultracentrifuged again at $100,000 \mathrm{~g}$ for 45 minutes. The resulting supernatant (S3) was collected and protein content determined by Bradford assay. For analysis of NFATc3 and NFATc4 nuclear translocation, cytoplasmic and nuclear fractions were prepared as previously described (82). Briefly, frozen tissue was homogenized at $4^{\circ} \mathrm{C}$ with a glass tissue grinder in a buffer containing $10 \mathrm{mM}$ HEPES pH 7.9, $10 \mathrm{mM} \mathrm{KCl}, 0.1 \mathrm{mM}$ EDTA, $0.1 \mathrm{mM}$ EGTA, $2.5 \mathrm{mM}$ DTT, protease inhibitors cocktail (Roche), $1 \mathrm{mM}$ sodium orthovanadate, $1 \mu \mathrm{M}$ okadaic acid, $5 \mathrm{mM}$ sodium pyrophosphate, and $30 \mathrm{mM} \beta$-glycerophosphate. After leaving tubes for 15 minutes on ice, NP-40 was added to a final concentration of $0.6 \%$ and mixed for 10 seconds in a vortex. Then, samples were centrifuged at $14,000 \mathrm{~g}$ for 1 minute at $4^{\circ} \mathrm{C}$. Supernatants that constituted the cytosolic fraction were immediately frozen and stored at $-80^{\circ} \mathrm{C}$. To resuspend pellet, a buffer containing $20 \mathrm{mM}$ HEPES pH 7.9, 25\% glycerol, $0.4 \mathrm{M} \mathrm{NaCl}, 1 \mathrm{mM}$ EDTA, $1 \mathrm{mM}$ EGTA, $2.5 \mathrm{mM}$ DTT, protease inhibitor cocktail (Roche), $1 \mathrm{mM}$ sodium orthovanadate, $1 \mu \mathrm{M}$ okadaic acid, $5 \mathrm{mM}$ sodium pyrophosphate, and $30 \mathrm{mM} \beta$-glycerophosphate was added. Then tubes were agitated gently with a vortex for 10 minutes at $4^{\circ} \mathrm{C}$. Finally, samples were centrifuged at $14,000 \mathrm{~g}$ for 5 minutes at $4^{\circ} \mathrm{C}$, and supernatants that constituted the nuclear fraction were immediately frozen and stored at $-80^{\circ} \mathrm{C}$. In each case, $15-30 \mu \mathrm{g}$ of total protein was electrophoresed on $10 \%$ SDS-polyacrylamide gel and transferred to a nitrocellulose membrane (Schleicher and Schuell). The experiments were performed using the following primary antibodies:
anti-pSer21/9-GSK-3 $\alpha / \beta$ (1:500) and anti-GSK-3 $\alpha / \beta$ (1:1,000), anti-PHF-1 (1:100), anti- $\beta$-actin $(1: 5,000)$, anti-NFATc3 (A-17) (1:200), anti-NFATc4 (Abcam) (1:200), anti-Hsp90 (1:500), anti-lamin B1 (1:200), and anti-FasL (1:50). The membranes were incubated with antibody overnight at $4{ }^{\circ} \mathrm{C}$ in $5 \%$ nonfat dried milk (anti-GSK-3 $\beta$ ) or $5 \%$ BSA (pSer21/9-GSK-3 $\alpha / \beta)$. Secondary antibodies used were polyclonal rabbit anti-mouse immunoglobulins/HRP or polyclonal rabbit anti-rabbit immunoglobulins/HRP (Dako) (1:2,000), and ECL detection reagents (PerkinElmer) were used for immunodetection.

Immunohistochemistry and immunofluorescence. Mice were sacrificed using $\mathrm{CO}_{2}$ and brains immediately removed and dissected on an ice-cold plate. Left hemispheres were processed for histology, placed in $4 \%$ paraformaldehyde in Sorensen's phosphate buffer (PFA) overnight, and then immersed in $30 \%$ saccharose in PBS for 72 hours. Once cryoprotected, the samples were frozen and stored at $-80^{\circ} \mathrm{C}$ until use. Sagittal sections $(30 \mu \mathrm{m})$ were cut on a CM 1950 Ag Protect freezing microtome (Leica) and collected and stored free-floating in glycol at $-20^{\circ} \mathrm{C}$. For immunohistochemistry, brain sections were pretreated for 30 minutes in $1 \% \mathrm{H}_{2} \mathrm{O}_{2} / \mathrm{PBS}$, followed by 1 hour with $1 \%$ BSA, $5 \%$ FBS, and $0.2 \%$ Triton X-100, and incubated overnight at $4{ }^{\circ} \mathrm{C}$ with primary antibodies at the following concentrations: cleaved caspase- 3 (1:50), NFATc4 (1:100), NFATc3 (1:100), and FasL (1:300). Finally, brain sections were incubated in avidin-biotin complex using the Elite Vectastain kit (Vector Laboratories). Chromogen reactions were performed with diaminobenzidine (SIGMAFAST DAB, Sigma-Aldrich) for 10 minutes. Sections were mounted on glass slides and coverslipped with FluorSave (Calbiochem). For quantification of immunostainings, 4 sagittal sections matching the lateral $1.92 \mathrm{~mm}, 1.80 \mathrm{~mm}, 1.68 \mathrm{~mm}$, and $1.56 \mathrm{~mm}$ planes as described by Paxinos and Franklin (83) were selected from each animal. All analyses were performed in a blinded manner, and results were presented as number of immunoreactive cells per $30-\mu \mathrm{m}$ section. The number of animals included in each analysis is specified in the corresponding figure legend.

For immunofluorescence, $30-\mu \mathrm{m}$ sagittal brain sections matching the $1.80-\mathrm{mm}$ plane as described by Paxinos and Franklin (83) were pretreated with $0.1 \%$ Triton X-100 for 15 minutes, $1 \mathrm{M}$ glycine for 30 minutes, and blocking solution (1\% BSA and $0.1 \%$ Triton X-100) for 1 hour. Sections were then incubated overnight at $4{ }^{\circ} \mathrm{C}$ with primary antibodies at the following concentrations: cleaved caspase-3 (1:50), NeuN (1:100), GFAP (1:1,000), Iba-1 (1:500), FasL (1:300), pSer21/9-GSK-3 $\alpha / \beta$ (1:100), NFATc3 (1:100), and NFATc4 (1:100). The following day, sections were washed in PBS and incubated with the following secondary antibodies, respectively, for 1 hour: goat anti-mouse Alexa Fluor 488, donkey anti-rabbit Alexa Fluor 488, donkey anti-rabbit Alexa Fluor 594, and donkey anti-goat Alexa Fluor 555 (1:400) (Invitrogen). For amplification of cleaved caspase-3 and FasL signal, biotinylated secondary antibody (Elite, Vectastain) and Streptavidin Alexa Fluor 555 (Invitrogen) (1:400) were used. Finally, nuclei were stained by using DAPI $(1: 5,000)$ (Calbiochem). Sections were mounted on glass slides, coverslipped with FluorSave, and maintained at $4^{\circ} \mathrm{C}$.

Colocalization of markers was identified by taking successive Alexa Fluor 594 and Alexa Fluor 488 fluorescence images using an Axioskop 2 Plus (Zeiss) microscope and CCD camera (Coolsnap FX color, Roper Scientific) or using a Laser Confocal LSM710 camera (Zeiss) coupled to an inverted microscope AxioObserver (Zeiss).

For quantitative analysis of NFATc 3 and NFATc 4 nuclear staining, $30-\mu \mathrm{m}$ sagittal sections were scanned with an inverted AxioObserver microscope (Zeiss) using a ×40/1.30 EC "Plan-Neofluar" Oil DIC M27 objective, and, for each field, a $1 \mu \mathrm{m}$-thick image was taken with a Laser Confocal LSM710 camera using diode $405 \mathrm{~nm}$ (blue), argon $488 \mathrm{~nm}$ (green), and DPSS $561 \mathrm{~nm}$ (red) lasers, with the same capture conditions maintained for all images in a given region. For subsequent fluorescence intensity analysis in the collected images, the $1.42 \mathrm{q}$ version of ImageJ software (http://rsbweb.nih.gov/ij/) was used as follows: first, the program's Triangle algorithm was used to dis- 
criminate positive NFATc (green) signal over background. Neuronal identity of these cells was verified according to NeuN (red) costaining. Then, DAPI images (blue) were converted to grayscale and the ImageJ-Maximum filter set at a radius of 2 pixels for clearer identification of the nuclear outline. Regions corresponding to nuclei (based on DAPI counterstaining) were selected using the Free-hand tool to delineate the outline. These regions were then superimposed upon the NFATc image, and an adjacent cytoplasm area was also delineated for each cell with the Free-hand tool. Similarly, a neuropil region was also selected for each image for background mean intensity $(b)$. Then, mean fluorescence intensity was measured for each nuclear area $\left(n_{1}-n_{n}\right)$ and each cytoplasmic area $\left(c_{1}-c_{n}\right)$. Finally, we classified a nucleus as positive for increased NFATc 3 or NFATc 4 when, upon background subtraction, nuclear intensity exceeded $0.75 \times$ cytoplasmic intensity $\left(\left[n_{x}-b\right] /\left[c_{x}-b\right]>0.75\right)$.

All analyses were performed in a blinded manner, and results were presented as number of immunopositive cells per $30-\mu \mathrm{m}$ section. The number of animals included in each analysis is specified in the corresponding figure legend.

TUNEL assay. Sections were processed according to the In Situ Cell Death Detection Kit protocol (POD, Roche). Quantification was performed at 1.80-mm planes as described by Paxinos and Franklin (83) All analyses were performed in a blinded manner, and results were presented as the number of TUNEL-positive cells per $30-\mu \mathrm{m}$ section. Twelve control and 10 lithiumtreated mice were analyzed.

Behavioral testing. Vertical pole testing was performed as previously described (84) with minor modifications (34). The mouse was placed head upward on the top of a vertical rough-surfaced pole (diameter, $1 \mathrm{~cm}$; height, $50 \mathrm{~cm}$ ), and the time taken to descend to the floor was recorded, with a maximum duration of 60 seconds.

Treadmill gait analysis. Gait analysis was performed using the DigiGait system (Mouse Specifics Inc.) (85). Briefly, digital images of paw placement were recorded at $80 \mathrm{~Hz}$ through a clear treadmill from beneath the animal. Mice were tested without pretraining in 1 session at a treadmill speed of $24 \mathrm{~cm} / \mathrm{s}$. Paws were marked with red colorant for better contrast. Plotting the area of each digital paw print imaged sequentially in time provides a dynamic gait signal, representing the temporal record of paw placement relative to the treadmill belt. Stride length was calculated from the fixed walking speed divided by the measured stride frequency (strides per second) as described previously (85).
Stride length variation was measured as the standard deviation of the stride length for the set of strides recorded (reflecting the dispersion about the average value). Step angle variation was measured as coefficient of variation (CV) and was calculated using the formula: $100 \times \mathrm{SD} /$ mean value (variability normalized to the mean). Step angle factors both stance width and stride length. Stance asymmetry is the ratio of left hind limb to right hind limb stance.

Statistics. Statistical analysis was performed with SPSS 17.0. Data are presented as mean values \pm SEM. The normality of the data was analyzed by Kolmogorov-Smirnov test. Statistical analysis of data with a normal distribution was performed by using a 1-way ANOVA test followed by a Bonferroni post-hoc test. Statistical significance of nonparametric data was determined by Mann-Whitney $U$ test. The level of significance accepted was $P<0.05$.

\section{Acknowledgments}

The authors thank F. Hernández for invaluable help at every stage of this research; J. Avila for helpful suggestions on many aspects of this research and for critical reading of the manuscript; M. Fresno and his team and J.M. Redondo for advice on NFAT physiology and research tools; J. Molkentin for providing NFATc4-knockout mice; L. Glimcher for agreeing to share the NFATc3-knockout mice and F. Granucci for providing them; J. Diaz-Nido and F. Wandosell for helpful discussion and comments; and O. Howard for comments and style correction. We are also grateful to Javier Palacín, Desireé Ruiz, and Alicia Tomico for technical assistance. This work was supported by CIBERNED (Instituto de Salud Carlos III), by grants from Ministerio de Ciencia (MEC, MICINN) and Comunidad Autónoma de Madrid, and by an institutional grant from Fundación Ramón Areces.

Received for publication October 1, 2009, and accepted in revised form April 21, 2010.

Address correspondence to: José J. Lucas, Centro de Biología Molecular "Severo Ochoa," CSIC/UAM, Campus UAM de Cantoblanco, 28049 Madrid, Spain. Phone: 34.91.196.4552, 34.91.196.4582; Fax: 34.91.196.4420; E-mail: jjlucas@cbm.uam.es.
1. Manji HK, Moore GJ, Chen G. Lithium at 50: have the neuroprotective effects of this unique cation been overlooked? Biol Psychiatry. 1999;46(7):929-940.

2. Baldessarini RJ, Tondo L, Hennen J, Viguera AC. Is lithium still worth using? An update of selected recent research. Harv Rev Psychiatry. 2002;10(2):59-75.

3. Kovacsics CE, Gottesman II, Gould TD. Lithium's antisuicidal efficacy: elucidation of neurobiological targets using endophenotype strategies. Annu Rev Pharmacol Toxicol. 2009;49:175-198.

4. Grof P, Muller-Oerlinghausen B. A critical appraisal of lithium's efficacy and effectiveness: the last 60 years. Bipolar Disord. 2009;11(suppl 2):10-19.

5. Macritchie KAN, Young AH. Adverse syndromes associated with lithium. In Haddad P, Dursun S, Deakin B, eds. Adverse Syndromes and Psychiatric Drugs: A Clinical Guide. New York, New York, USA: Oxford University Press; 2004:89-109.

6. Woodgett JR. Molecular cloning and expression of glycogen synthase kinase-3/factor A. EMBO J. 1990;9(8):2431-2438.

7. Jope RS, Johnson GV. The glamour and gloom of glycogen synthase kinase-3. Trends Biochem Sci. 2004;29(2):95-102.

8. Grimes CA, Jope RS. The multifaceted roles of glycogen synthase kinase 3 beta in cellular signaling. Prog Neurobiol. 2001;65(4):391-426.

9. Hooper C, Killick R, Lovestone S. The GSK3 hypothesis of Alzheimer's disease. J Neurochem. 2008;104(6):1433-1439.
10. Takashima A. GSK-3 is essential in the pathogenesis of Alzheimer's disease. J Alzheimers Dis. 2006; 9(3 suppl):309-317.

11. Lovestone $\mathrm{S}$, et al. Alzheimer's disease-like phosphorylation of the microtubule-associated protein tau by glycogen synthase kinase- 3 in transfected mammalian cells. Curr Biol. 1994;4(12):1077-1086.

12. Munoz-Montano JR, Moreno FJ, Avila J, DiazNido J. Lithium inhibits Alzheimer's disease-like tau protein phosphorylation in neurons. FEBS Lett. 1997;411(2-3):183-188

13. Phiel CJ, Wilson CA, Lee VM, Klein PS. GSK-3alpha regulates production of Alzheimer's disease amyloidbeta peptides. Nature. 2003;423(6938):435-439.

14. Takashima A, Noguchi K, Sato K, Hoshino T, Imahori $\mathrm{K}$. Tau protein kinase I is essential for amyloid beta-protein-induced neurotoxicity. Proc Natl Acad Sci U S A. 1993;90(16):7789-7793.

15. Lucas JJ, Hernandez F, Gomez-Ramos P, Moran MA, Hen R, Avila J. Decreased nuclear beta-catenin, tau hyperphosphorylation and neurodegeneration in GSK-3beta conditional transgenic mice. EMBOJ. 2001;20(1-2):27-39.

16. Engel T, Hernandez F, Avila J, Lucas JJ. Full reversal of Alzheimer's disease-like phenotype in a mouse model with conditional overexpression of glycogen synthase kinase-3. J Neurosci. 2006;26(19):5083-5090.

17. Engel T, Goni-Oliver P, Gomez de Barreda E, Lucas JJ, Hernandez F, Avila J. Lithium, a potential protective drug in Alzheimer's disease. Neurodegener
Dis. 2008;5(3-4):247-249.

18. Mazanetz MP, Fischer PM. Untangling tau hyperphosphorylation in drug design for neurodegenerative diseases. Nat Rev Drug Discov. 2007;6(6):464-479.

19. Macdonald A, Briggs K, Poppe M, Higgins A, Velayudhan L, Lovestone S. A feasibility and tolerability study of lithium in Alzheimer's disease. Int J Geriatr Psychiatry. 2008;23(7):704-711.

20. Engel T, Goni-Oliver P, Lucas JJ, Avila J, Hernandez F. Chronic lithium administration to FTDP-17 tau and GSK-3beta overexpressing mice prevents tau hyperphosphorylation and neurofibrillary tangle formation, but pre-formed neurofibrillary tangles do not revert. J Neurochem. 2006;99(6):1445-1455.

21. Paquet $D$, et al. A zebrafish model of tauopathy allows in vivo imaging of neuronal cell death and drug evaluation. J Clin Invest. 2009;119(5):1382-1395.

22. Brinkman SD, Pomara N, Barnett N, Block R, Domino EF, Gershon S. Lithium-induced increases in red blood cell choline and memory performance in Alzheimer-type dementia. Biol Psychiatry. 1984;19(2):157-164.

23. Pomara N. Lithium treatment in Alzheimer's disease does not promote cognitive enhancement, but may exert long-term neuroprotective effects. Psychopharmacology (Berl). 2009;205(1):169-170.

24. Klein PS, Melton DA. A molecular mechanism for the effect of lithium on development. Proc Natl Acad Sci U S A. 1996;93(16):8455-8459.

25. Stambolic V, Ruel L, Woodgett JR. Lithium inhib- 
its glycogen synthase kinase-3 activity and mimics wingless signalling in intact cells. Curr Biol. 1996;6(12):1664-1668.

26. Ryves WJ, Harwood AJ. Lithium inhibits glycogen synthase kinase-3 by competition for magnesium. Biochem Biophys Res Commun. 2001;280(3):720-725.

27. De Sarno P, Li X, Jope RS. Regulation of Akt and glycogen synthase kinase- 3 beta phosphorylation by sodium valproate and lithium. Neuropharmacology. 2002;43(7):1158-1164.

28. Chalecka-Franaszek E, Chuang DM. Lithium activates the serine/threonine kinase Akt-1 and suppresses glutamate-induced inhibition of Akt1 activity in neurons. Proc Natl Acad Sci U S A. 1999;96(15):8745-8750.

29. Jope RS. Lithium and GSK-3: one inhibitor, two inhibitory actions, multiple outcomes. Trends Pharmacol Sci. 2003;24(9):441-443.

30. Noble W, et al. Inhibition of glycogen synthase kinase- 3 by lithium correlates with reduced tauopathy and degeneration in vivo. Proc Natl Acad Sci US A. 2005;102(19):6990-6995.

31. Beaulieu JM, et al. A beta-arrestin 2 signaling complex mediates lithium action on behavior. Cell. 2008;132(1):125-136.

32. Zhang F, Phiel CJ, Spece L, Gurvich N, Klein PS Inhibitory phosphorylation of glycogen synthase kinase-3 (GSK-3) in response to lithium. Evidence for autoregulation of GSK-3. J Biol Chem. 2003;278(35):33067-33077.

33. Szatmari E, Habas A, Yang P, Zheng JJ, Hagg T, Hetman M. A positive feedback loop between glycogen synthase kinase 3 beta and protein phosphatase 1 after stimulation of NR2B NMDA receptors in forebrain neurons. J Biol Chem. 2005;280(45):37526-37535.

34. Gomez-Sintes R, et al. Neuronal apoptosis and reversible motor deficit in dominant-negative GSK-3 conditional transgenic mice. EMBO J. 2007;26(11):2743-2754.

35. Bersudsky Y, Shaldubina A, Belmaker RH. Lithium's effect in forced-swim test is blood level dependent but not dependent on weight loss. Behav Pharmacol. 2007;18(1):77-80.

36. Brooks SP, Dunnett SB. Tests to assess motor phenotype in mice: a user's guide. Nat Rev Neurosci. 2009;10(7):519-529.

37. Hausdorff JM, Lertratanakul A, Cudkowicz ME, Peterson AL, Kaliton D, Goldberger AL. Dynamic markers of altered gait rhythm in amyotrophic lateral sclerosis. J Appl Physiol. 2000;88(6):2045-2053.

38. Amende I, Kale A, McCue S, Glazier S, Morgan JP, Hampton TG. Gait dynamics in mouse models of Parkinson's disease and Huntington's disease. J Neuroeng Rehabil. 2005;2:20.

39. Lin $\mathrm{CH}$, et al. Neurological abnormalities in a knock-in mouse model of Huntington's disease. Hum Mol Genet. 2001;10(2):137-144.

40. Beurel E, Jope RS. The paradoxical pro- and antiapoptotic actions of GSK3 in the intrinsic and extrinsic apoptosis signaling pathways. Prog Neurobiol. 2006;79(4):173-189.

41. Ashkenazi A, Dixit VM. Death receptors: signaling and modulation. Science. 1998;281(5381):1305-1308.

42. Beyaert R, Vanhaesebroeck B, Suffys P, Van Roy F, Fiers W. Lithium chloride potentiates tumor necrosis factor-mediated cytotoxicity in vitro and in vivo. Proc Natl Acad Sci U S A. 1989;86(23):9494-9498.

43. Hoeflich KP, Luo J, Rubie EA, Tsao MS, Jin O, Woodgett JR. Requirement for glycogen synthase kinase-3beta in cell survival and NF-kappaB activation. Nature. 2000;406(6791):86-90.

44. Liao X, Zhang L, Thrasher JB, Du J, Li B. Glycogen synthase kinase-3beta suppression eliminates tumor necrosis factor-related apoptosis-inducing ligand resistance in prostate cancer. Mol Cancer Ther. 2003;2(11):1215-1222.

45. Rottmann S, Wang Y, Nasoff M, Deveraux QL, Quon KC. A TRAIL receptor-dependent synthetic lethal relationship between MYC activation and GSK3beta/FBW7 loss of function. Proc Natl Acad Sci U S A. 2005;102(42):15195-15200.

46. Song L, Zhou T, Jope RS. Lithium facilitates apoptotic signaling induced by activation of the Fas death domain-containing receptor. BMC Neurosci. 2004:5:20.

47. Beals CR, Sheridan CM, Turck CW, Gardner P, Crabtree GR. Nuclear export of NF-ATc enhanced by glycogen synthase kinase-3. Science. 1997;275(5308):1930-1934.

48. Beals CR, Clipstone NA, Ho SN, Crabtree GR. Nuclear localization of NF-ATc by a calcineurindependent, cyclosporin-sensitive intramolecular interaction. Genes Dev. 1997;11(7):824-834.

49. Graef IA, et al. L-type calcium channels and GSK3 regulate the activity of NF-ATc4 in hippocampal neurons. Nature. 1999;401(6754):703-708.

50. Rengarajan J, et al. Sequential involvement of NFAT and Egr transcription factors in FasL regulation. Immunity. 2000;12(3):293-300.

51. Vihma H, Pruunsild P, Timmusk T. Alternative splicing and expression of human and mouse NFAT genes. Genomics. 2008;92(5):279-291.

52. Jayanthi $S$, et al. Calcineurin/NFAT-induced up-regulation of the Fas ligand/Fas death pathway is involved in methamphetamine-induced neuronal apoptosis. Proc Natl Acad Sci U S A. 2005;102(3):868-873.

53. Graef IA, et al. Neurotrophins and netrins require calcineurin/NFAT signaling to stimulate outgrowth of embryonic axons. Cell. 2003;113(5):657-670.

54. Fan Y, et al. Regulation of the stability and transcriptional activity of NFATc4 by ubiquitination. FEBS Lett. 2008;582(29):4008-4014.

55. Qiu J, et al. Upregulation of the Fas receptor death-inducing signaling complex after traumatic brain injury in mice and humans. J Neurosci. 2002;22(9):3504-3511.

56. Kiani A, Rao A, Aramburu J. Manipulating immune responses with immunosuppressive agents that target NFAT. Immunity. 2000;12(4):359-372.

57. Cohen PL, Eisenberg RA. Lpr and gld: single gene models of systemic autoimmunity and lymphoproliferative disease. Annu Rev Immunol. 1991;9:243-269.

58. Watson ML, et al. Genetic analysis of MRL-lpr mice: relationship of the Fas apoptosis gene to disease manifestations and renal disease-modifying loci. J Exp Med. 1992;176(6):1645-1656.

59. Gould TD, Quiroz JA, Singh J, Zarate CA, Manji HK. Emerging experimental therapeutics for bipolar disorder: insights from the molecular and cellular actions of current mood stabilizers. Mol Psychiatry. 2004;9(8):734-755.

60. O'Brien WT, et al. Glycogen synthase kinase3beta haploinsufficiency mimics the behavioral and molecular effects of lithium. J Neurosci. 2004;24(30):6791-6798.

61. Chuang DM, et al. Neuroprotective effects of lithium in cultured cells and animal models of diseases. Bipolar Disord. 2002;4(2):129-136.

62. Beaulieu JM, et al. Lithium antagonizes dopaminedependent behaviors mediated by an AKT/glycogen synthase kinase 3 signaling cascade. Proc Natl Acad Sci U S A. 2004;101(14):5099-5104.

63. Kondo E, et al. NF-ATc2 induces apoptosis in Burkitt's lymphoma cells through signaling via the B cell antigen receptor. Eur Immunol. 2003;33(1):1-11.

64. Luoma JI, Zirpel L. Deafferentation-induced activation of NFAT (nuclear factor of activated T-cells) in cochlear nucleus neurons during a developmental critical period: a role for NFATc4dependent apoptosis in the CNS. J Neurosci. 2008;28(12):3159-3169.

65. Sun M, Song L, Li Y, Zhou T, Jope RS. Identification of an antiapoptotic protein complex at death receptors. Cell Death Differ. 2008;15(12):1887-1900.

66. Naesens M, Kuypers DR, Sarwal M. Calcineurin inhibitor nephrotoxicity. Clin J Am Soc Nephrol. 2009;4(2):481-508

67. Kim WY, et al. GSK-3 is a master regulator of neural progenitor homeostasis. Nat Neurosci. 2009;12(11):1390-1397.

68. Diaz-Hernandez M, et al. Full motor recovery despite striatal neuron loss and formation of irreversible amyloid-like inclusions in a conditional mouse model of Huntington's disease. J Neurosci. 2005;25(42):9773-9781.

69. Eldar-Finkelman H. Glycogen synthase kinase 3: an emerging therapeutic target. Trends $\mathrm{Mol} \mathrm{Med.}$ 2002;8(3):126-132.

70. Fornai F, et al. Lithium delays progression of amyotrophic lateral sclerosis. Proc Natl Acad Sci U S A. 2008;105(6):2052-2057.

71. Fornai F, Siciliano G, Manca ML, Murri L, Paparelli A, Ruggieri S. Lithium in ALS: from the bench to the bedside. Amyotroph Lateral Scler. 2008;9(2):123-124.

72. Haase G, Pettmann B, Raoul C, Henderson CE. Signaling by death receptors in the nervous system. Curr Opin Neurobiol. 2008;18(3):284-291.

73. Gill A, Kidd J, Vieira F, Thompson K, Perrin S. No benefit from chronic lithium dosing in a siblingmatched, gender balanced, investigator-blinded trial using a standard mouse model of familial ALS. PLoS One. 2009;4(8):e6489.

74. Hampel H, et al. Lithium trial in Alzheimer's disease: a randomized, single-blind, placebo-controlled, multicenter 10-week study. J Clin Psychiatry. 2009;70(6):922-931.

75. Oukka M, Ho IC, de la Brousse FC, Hoey T, Grusby MJ, Glimcher LH. The transcription factor NFAT4 is involved in the generation and survival of T cells. Immunity. 1998;9(3):295-304.

76. Wilkins BJ, et al. Targeted disruption of NFATc3, but not NFATc4, reveals an intrinsic defect in calcineurin-mediated cardiac hypertrophic growth. Mol Cell Biol. 2002;22(21):7603-7613.

77. Anson RM, et al. Intermittent fasting dissociates beneficial effects of dietary restriction on glucose metabolism and neuronal resistance to injury from calorie intake. Proc Natl Acad Sci U S A. 2003;100(10):6216-6220.

78. Kondo $M$, et al. Caloric restriction stimulates revascularization in response to ischemia via adiponectin-mediated activation of endothelial nitric-oxide synthase. J Biol Chem. 2009;284(3):1718-1724.

79. Wernig A, Irintchev A, Lange G. Functional effects of myoblast implantation into histoincompatible mice with or without immunosuppression. J Physiol. 1995;484(pt 2):493-504.

80. Frangsmyr L, Baranov V, Nagaeva O, Stendahl U, Kjellberg L, Mincheva-Nilsson L. Cytoplasmic microvesicular form of Fas ligand in human early placenta: switching the tissue immune privilege hypothesis from cellular to vesicular level. Mol Hum Reprod. 2005;11(1):35-41.

81. Martinez-Lorenzo MJ, et al. Activated human T cells release bioactive Fas ligand and APO2 ligand in microvesicles. J Immunol. 1999;163(3):1274-1281.

82. Diaz-Meco MT, Lallena MJ, Monjas A, Frutos S, Moscat J. Inactivation of the inhibitory kappaB protein kinase/nuclear factor kappaB pathway by Par-4 expression potentiates tumor necrosis factor alpha-induced apoptosis. J Biol Chem. 1999;274(28):19606-19612.

83. Paxinos G, Franklin KBJ. The Mouse Brain in Stereotaxic Coordinates. San Diego, California, USA: Academic Press; 2001.

84. Matsuura K, Kabuto H, Makino H, Ogawa N. Pole test is a useful method for evaluating the mouse movement disorder caused by striatal dopamine depletion. J Neurosci Methods. 1997;73(1):45-48.

85. Hampton TG, Stasko MR, Kale A, Amende I, Costa AC. Gait dynamics in trisomic mice: quantitative neurological traits of Down syndrome. Physiol Behav. 2004;82(2-3):381-389. 